Article

\title{
Fly Ash Modified Coalmine Solid Wastes for Stabilization of Trace Metals in Mining Damaged Land Reclamation: A Case Study in Xuzhou Coalmine Area
}

\author{
Jiu Huang ${ }^{1,2}$, Peng Wang ${ }^{2}$, Chaorong $\mathrm{Xu}^{1}$ and Zhuangzhuang $\mathrm{Zhu}{ }^{1, *}$ \\ 1 School of Environment Science and Spatial Informatics, China University of Mining and Technology, \\ 221116 Xuzhou, China; jhuang@cumt.edu.cn (J.H.); crxu@cumt.edu.cn (C.X.) \\ 2 State Key Laboratory for Geomechnics and Deep Underground Engineering, 221116 Xuzhou, China; \\ pwang@cumt.edu.cn \\ * Correspondence: zzzhu@cumt.edu.cn; Tel.: +86-178-51147681
}

Received: 14 August 2018; Accepted: 19 October 2018; Published: 21 October 2018

\begin{abstract}
In China, coalmine wastes, such as gangues, are used for reclamation of mining subsided land. However, as waste rocks, gangues contain several trace metal elements, which could be released under natural weathering and hydrodynamic leaching effects and then migrate into the reclamed soil layer. However, it is very difficult to find adequate other backfill materials for substitution of gangues. In this paper, we present a novel method and case study to restrict the migration ability of trace metal elements in gangues by using another kind of coalmine solid waste-fly ashes from coal combustion. In this study, fly ashes were mixed with gangues in different mass proportions 1:0.2, 1:0.4, 1:0.6 and 1:0.8 as new designed backfill materials. Due to the help of fly ash, the occurrence states of studied trace metal elements were greatly changed, and their releasing and migration ability under hydrodynamic leaching effect were also significantly restricted. In this research seven trace metal elements in gangues $\mathrm{Cu}, \mathrm{Zn}, \mathrm{Pb}, \mathrm{Cd}, \mathrm{Cr}, \mathrm{Mn}$ and $\mathrm{Ni}$ were studied by using soil column hydrodynamical leaching method and simulated precipitation for one year. The results show that under the driving of natural precipitation trace metal elements were generally transported deep inside the reconstructed land base, i.e., far away from soil layer and most of the trace metal elements were transformed into a bonded state, or combined in inert occurrence states, especially the residual state. With this method, the migration activities of tested trace metal elements were greatly restricted and the environmental potential risk could be significantly reduced.
\end{abstract}

Keywords: mining gangues; subsidence backfill; occurrence states transformation; element migration

\section{Introduction}

China is the biggest coal production and consumption country in the world. Coal occupies more than $70 \%$ domestic primary energy consumption in China, which covers about $75 \%$ primary fuels for industries and more than $90 \%$ primary fuels for civil use. Furthermore, in China, it is believed that coal will continued to be used as the main energy source for a long period in future [1-4]. Most coal is produced through underground mining in China, which makes use of a huge land area. Until now, there are more than $4.3 \times 10^{5} \mathrm{hm}^{2}$ mining subsidence area in China currently. Under actual technologies, with a coal yield of $10^{4} \mathrm{t}$ there are about $0.2 \mathrm{hm}^{2}$ subsidence of land resource. The annual increment of mining subsidence area is about $5 \times 10^{4} \mathrm{hm}^{2}$ [2-4]. Meanwhile, coal mining has also generated huge amount of solid wastes, mainly waste rocks (coal gangues). Conventionally the coalmine gangues are disposed in dumps. At present, in China there are about 4.5 billion tons of 
coalmine solid wastes are stored in dumps: worse still is that the dumps keep increasing around 0.95 billion tons/year. At present, there are totally about 1500 coalmine waste dumps in China, which occupy more than $8 \times 10^{4} \mathrm{hm}^{2}$ land areas [5-9]. Mining subsidence and dumps destroy land resources and make them to be unavailable for any uses. Therefore, since the 1980s in China mining solid wastes had been used for reclamation of mining subsidence area, which is called backfill reclamation, which has been proved to be effective both in remediation of subsided land and disposal of mining solid wastes. Mining solid wastes consists mostly of waste rocks, which are produced during coal production and coal processing. Gangues take $15-40 \%$ mass of raw coals after wash-refining [10-12]. Coalmine wastes have huge yields in local areas e.g., in Xuzhou City, which has a coal mining history of more than 130 years; only huge amounts of gangues could fulfill the demands of backfill materials in large subsided area [1,2,13-15]. The subsided land reclamation could be divided into three processes: "reshaping", "resoiling" and "replanting" [1,2,4-7]. For backfill reclamation, the mining solid wastes are only used for "reshaping" of subsided land, i.e., they constitute the base material of overlaying soil layers to upraise the surface to achieve ground level, on which the plants are rehabilitated. Gangues are rock materials, they are suitable for reconstruction of land base aggregate. However, for base reconstruction, fine materials, such as sands, are also necessary to ensure air permeability and water retention ability $[7,10,12,14]$. However, quantity of sands is limited according to regions, they are also relative too expensive. Together with coalmine there are always coal combustion power plants which could supply fly ashes with adequate amount as backfill material, fly ashes have very fine particle sizes and large surface areas.

Gangues and fly ash also contain several kinds of trace metals such like lead $(\mathrm{Pb})$, cadmium $(\mathrm{Cd})$, chromium $(\mathrm{Cr})$, manganese $(\mathrm{Mn})$, nickel $(\mathrm{Ni})$, copper $(\mathrm{Cu})$, zinc $(\mathrm{Zn})$ etc., which are always hazardous to overlaying soil layers. In China, the "Directives of land resource reclamation" had regulated that among use types of reclaimed land, the agricultural use has the highest priority $[2,4-7,13,14]$. Related researchers have pointed out that there are risks of the trace metal elements releasing from mining wastes, as well as probabilities of migration into the plants and crops under certain circumstance conditions of reconstructed soil layers $[4,5,12,13,16-18]$. Trace metal elements could bring great threaten to human health. $\mathrm{Pd}$ and $\mathrm{Cr}$, for example, $\mathrm{Pd}$ could lead to anemia and cause damage to the nervous system; Cr could destroy renal function, cause osteomalacia or even a cancer [19-23]. Therefore, most of the related researches concentrate on the release and migration behaviors of trace metals in reclaimed land. Their results have pointed out that trace metal elements in soil are much more difficult to migrate than in air and water, since the soil organic and inorganic colloidal particles have intensive adsorption and chelation effects on trace metals, which strongly limit their migration $[2,5,8,16]$. Most of the research in trace metal elements' migration has pointed out that the release and migration behaviors are actuated by hydrodynamic leaching behavior, i.e., the soaking effect of groundwater and the leaching effect of precipitation [2,4,14,16-21]. According to previous studies, some of them show that there were low risks on trace metal elements' migration [2,5,11]; the most common results demonstrate that with specific methods the potentials of trace metal contaminations could be effectively restricted and controlled [2,5,12,16-25]; and some of them reported that there were always high contaminations or potential of threatens [26-28]. O'Conner et al. $[15,18]$ has reported that with method of adsorption by using biochar material could achieve perfect solidification of trace metals, but in our situation, it is impossible to obtain adequate biochar for several tens of square kilometer area. Wang et al. [20,21] have verified that with binding materials like $\mathrm{MgO}$, several kinds of trace metals could be successfully stabilized. Weber et al. [22] and Żołnierz et al. [23] also reported that soil could be reconstructed by using fly ash over long periods. Actually, fly ash contains high proportion of metal oxides like $\mathrm{MgO}$, which could be a nice material for trace metal binding. According to the studies of $[21,22]$ on tremendous yield of fly ash from coal combustion power plants, the quantity requirements for large area reclamation could be guaranteed. However, fly ash comes from coal combustion, it contains also trace metals from coals. What will happen if the coal gangues are used together with fly ash in land reclamation? It is still a question to be studied. Most arguments in previous studies concentrated on 
the occurrence states variation of trace metal elements under natural hydrodynamic processes [29-32]. Variation of trace metals' contents could not represent their migration potential, we should also consider the overall occurrence states changing, i.e., the migration abilities of hazardous trace metals. To our knowledge, no work has been reported on trace metals' occurrence states' transformation in reclaimed land and soil, especially regarding reclamation by using fly ash modified mining waste rock materials.

The occurrence state of trace elements usually refers to their binding and combination states, i.e., the presence of trace elements [33]. As people pay more and more attention to the environment, the research on the states of trace elements has received much more attention. The potential harmfulness, toxicity, migration and transformation of hazardous trace elements into environment has become a key points in research field. In addition to total amount of elements, occurrence state is also a key issue. There is no authoritative and unified classification of trace elements' occurrence states. For coalmine solid wastes, the occurrence states of hazardous trace elements are very complicated [32-35]. The ways in which they combined with other substances and minerals determine their releasing and migration abilities into environment. Furthermore, their occurrence states could also be converted with the variation of physical-chemical conditions in soil and geological mediums.

Several kinds of methods have been developed for study of occurrence state, such as chemical sequential extraction, diffusive gradients in thin-films (DGT), spectral analysis, low temperature ignition, etc. Methods like DGT, which was commonly used in detection of trace metals in water and sediments, it is not suitable for analysis of trace metals in solid materials like coal gangue [36,37]; spectral analysis like nuclear magnetic resonance (NMR), electronic spectroscopy, were direct methods for trace metal detection, which were suitable for determining trace metal contents in coal with high precision; however, for occurrence states it was not accurate enough [38]; low temperature ignition was also a common method, which has similar limitation to spectral analysis in detection of occurrence states [39]. Therefore, for rock materials coming from coalmines in this research, we need to study series of substances and minerals combined with trace metals in different occurrence states, the method of sequential extraction is the most appropriate one. In recent years, the sequential extraction method has been widely used in the study of trace elements' occurrence states. This method is able to examine occurrence states in high accuracy. It dispels solid samples into specific solutions under certain chemical conditions, and then determines how trace elements' concentrations in the solution could represent their occurrence state in solid materials. With the modern measurement technologies, the sequential extraction method has achieved very high accuracy, especially together with mass spectroscopy method. Herein we present a method with occurrence states study by using sequential extraction to analyze the environmental risks on releasing and migration of trace metal elements from gangue-fly ash combined backfill materials. This study was designed according to an actual coalmine subsidence area near Xuzhou city, which will be soon reclaimed by using coalmine solid wastes.

\section{Materials and Methods}

\subsection{Study Area and Targets}

This research is based on a coalmine subsidence area on the east of the Xuzhou City, which locates around the Qishan-Quantai coalmine region of Xuzhou Coalmine Group $\left(34^{\circ} 20^{\prime} 01^{\prime \prime} \mathrm{N}, 117^{\circ} 24^{\prime} 20^{\prime \prime}\right.$ E), which is shown in Figure 1 as follows. At the end of 2017, all coalmines in this area were closed. The total subsidence area is about $8.2 \mathrm{~km}^{2}$, with average depth about $4.2 \mathrm{~m}$. Local government has planned to restore the subsided area for agricultural land. The reclamation will be implemented with backfill method by mainly using of coalmine solid wastes. After reclamation the groundwater level was designed to be $-2.0 \mathrm{~m}[2,14]$, and the thickness of the reclaimed soil layer was designed to be $20-30 \mathrm{~cm}$ [7]. Therefore, most of the backfilled coalmine wastes will be submerged in groundwater, and the distance between groundwater level and reconstructed soil layer is planned to be about $1.7-1.8 \mathrm{~m}[33,35]$. As we have mentioned, the migration ability of trace metal elements in water is much 
stronger than in soil, and with the draining of precipitation, the migration of trace metals happens inside the backfill material layer from the bottom of soil layer to the groundwater. In addition, the key point to this study is the occurrence state transformation and migration of trace metal elements under natural precipitation.

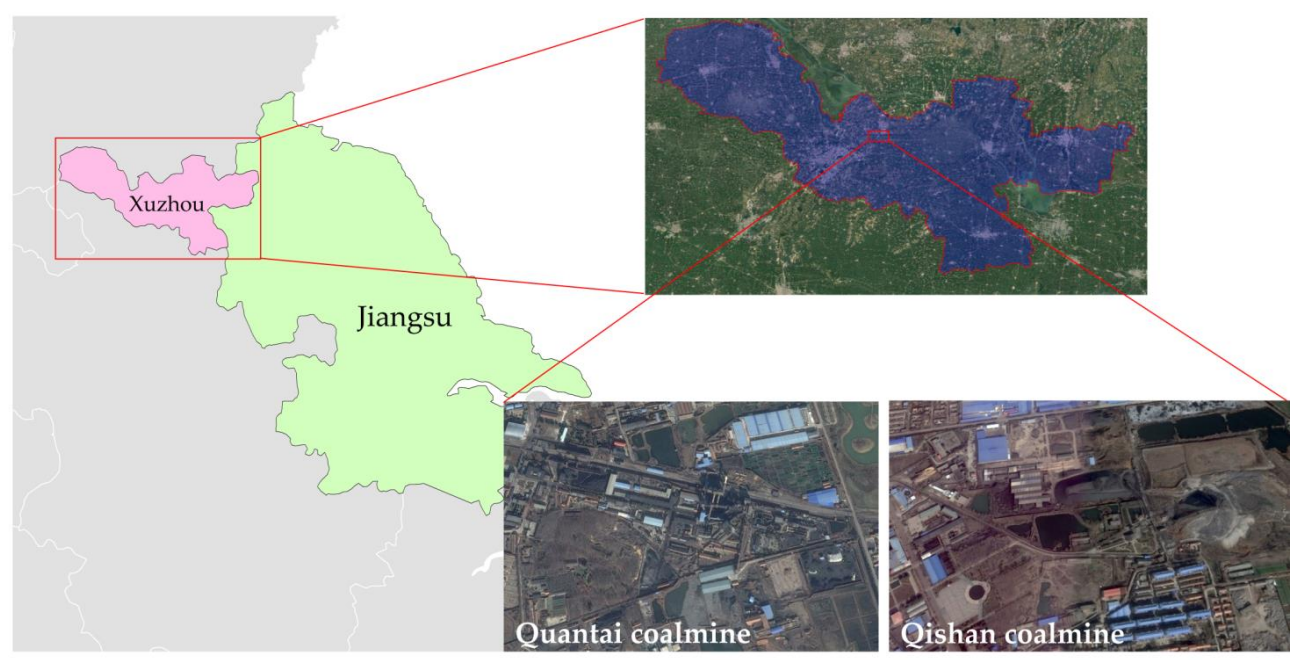

Figure 1. Location of Qishan-Quantai coalmines in Xuzhou City, Jiangsu Province.

\subsection{Standard Methods}

The studied backfill coalmine waste materials included gangue and fly ash were collected from coalmine and coal combustion power plants of Quantai-Qishan. Pure gangue has excellent performance as aggregate material but it has too high porosity and low water retention. Pure fly ash has too high $\mathrm{pH}$ value which always leads to soil slab, which strongly limits the water permeation. Hence in actual the gangue and fly ash are designed to be used with proportioning. Commonly there are several mass proportions between gangue and fly ash used, they are 1:0.2, 1:0.4, 1:0.6 and 1:0.8 according to different requirements in reclamation, respectively. Therefore, in this study we also study the occurrence state transformation and migration of trace metal elements in backfill materials with these above mentioned four mass proportions. According to the study purpose, five occurrence states of hazardous trace metals were studied to describe their migration abilities and their potential risks to the local environment:

\section{(1) Exchangeable state}

The exchangeable state is understood in most cases as the ionic state of adsorption-desorption effects of water. This state is the most active state to be transformed in the environment and result of great impact.

(2) Carbonates binding state

Elements that are capable to precipitate or co-precipitate as carbonate crystal, which can be released by mild acids, they are referred to be carbonates binding state. The $\mathrm{pH}$ value has significant effect on the migration ability of elements in this state, and acidic water can easily leach it. When the $\mathrm{pH}$ value decreased, the migration ability and biological activity of trace elements in this state will increase.

(3) Iron-manganese oxides combined state

Iron/manganese oxides or iron/manganese colloids can absorb or encapsulate trace elements in the sediment, such a state is called iron-manganese oxides binding states. Normally these kinds of binding states are stable, but the trace elements could be released under reductive conditions. This state is a reducible state. 
(4) Organic sulfide binding state

Elements with some states can only be extracted and released by using strong oxidants such as hydrogen peroxide and sodium pyrophosphate $\left(\mathrm{Na}_{4} \mathrm{P}_{2} \mathrm{O}_{7}\right)$; during the extraction process, these oxidants oxidize organics and sulfides in coal gangue samples. These elements can be co-precipitated with sulfide minerals or can be complexed with humic acids, fatty acids, alkanes, and other organic substances in the precipitate. Elements in this state are called organic sulfide binding states. The ions of harmful elements can produce concretion with the oxides, and the oxides themselves can also be transformed into particle capsules or inter-particle cements, which are due to their extremely strong adsorption. In the laboratory, the vast majority used oxidation is $30 \% \mathrm{H}_{2} \mathrm{O}_{2}$ solution, and then the extraction with ammonium acetate solution.

\section{(5) Residual state}

In addition to above mentioned four states, in backfill material there are certain trace metal binding substances with particularly high stability; therefore, they have no opportunity to be released and transported into environment. This kind of binding state can only be extracted with extreme conditions, like per-chloric acid or mixed strong acids as extractants. This binding state of trace metals is called residual state. In the laboratory, strong acid or mixed strong acid is usually used for the degradation and analysis of residual state elements.

Sequential extraction is an appropriate method to study the occurrence states' of trace elements.

\subsection{Digestion Analysis of Trace Metal Elements Content in Backfill Materials}

As an important basic of our study, the total trace elements' content in designed backfill material must be quantitative determined. Here we used chemical digestion analysis. The specific operations of experiment were as follows:

(1) Preparations:

We prepared $10 \%$ dilute nitric acid solution into a bucket and then submerged vessels to be used in this experiment in dilute nitric acid for $48 \mathrm{~h}$, then we cleaned the vessels with deionized water. Then they were dried in a drying oven.

(2) Experiment pretreatment:

Gangue material was crushed with a hammer mill, and $400 \mathrm{~g}$ crushed coal gangue powder were sampled and then fine grinded to particle size less than $0.1 \mathrm{~mm}$. Then every $100 \mathrm{~g}$ of each coal gangue powder were fully mixed with sampled fly ashes, according to the mass proportions between coal gangue and fly ash of 1:0.2, 1:0.4, 1:0.6, 1:0.8, respectively. Then we took $2 \mathrm{~g}$ of each sample for testing.

1. The tested gangue still contained little coal. Here we ignited the prepared samples at temperature of $650{ }^{\circ} \mathrm{C}$ for $8 \mathrm{~h}$ in muffle oven.

2. We took $0.5 \mathrm{~g}$ of each ignited sample into a Teflon cup, and added small amount of ultra-pure water into the sample to make it wet. Then we added concentrated hydrofluoric acid, concentrated nitric acid and per-chloric acid and placed it on a hot plate for digestion.

3. Until the sample had dissolved completely, we transferred the solution to a $25 \mathrm{~mL}$ volumetric flask for constant volume.

4. Then the digestion solutions were sent for analyses of trace metal concentrations by using Inductively Coupled Plasma Mass Spectrometry (ICP-MS), produced by Thermo-Fisher @), its detection limits and relative standard deviation (RSD) of trace elements were shown as follows in Table 1. This device has high analysis precisions for testing of heavy mass elements. 
Table 1. Detection limits and RSD of the applied ICP-MS.

\begin{tabular}{cccc}
\hline Elements & Light Mass Elements & Medium Mass Elements & Heavy Mass Elements \\
\hline Detection limits $(\mu \mathrm{mol} / \mathrm{kg})$ & $0.013-2.927$ & $0.053-0.413$ & $0.043-0.090$ \\
RSD $(\%)$ & $0.6-3.3$ & $0.8-1.2$ & $1.0-2.1$ \\
\hline
\end{tabular}

\subsection{Dynamic Leaching Study of Backfill Materials}

Backfill materials are mixtures of coal gangue and fly ash, the fly ash is dominated by fine particles, with similar properties of adsorptive clay, high content of trace metal elements and poor water solubility; for gangue material, it has high proportion of clay minerals, relative low content of trace metal elements and small proportion of soluble components. Natural leaching is the main process for the migration of trace metal elements into environment. During the leaching process, elements' releasing depends not only on their absolute content, but also on their occurrence states. Through the method of soil column dynamic leaching experiment, the present situation and transformation of trace metal elements' occurrence states under natural precipitation actuation could be studied. Soil column dynamic leaching method could be used for risk assessment of this method in different circumstances. It is an important method to study migration and state transformation of pollutants in soil and groundwater. It is widely used in research fields such as water conservancy, agriculture and soil science [40-42].

The soil column used in this experiment was made of polymethyl methacrylate (PMMA) material, which has high stability and corrosion resistance. The height of the column was $220 \mathrm{~cm}$, the cross-sectional diameter was $15 \mathrm{~cm}$, and the cross-sectional area was $176.71 \mathrm{~cm}^{2}$. The bottom of the soil column is connected with iron weights for stabilization. There is a permeable plate above the column bottom with a distance of $10 \mathrm{~cm}$. In addition to the screws between the base and the column body, it is also equipped with a seal to make it watertight. At the top of the column, there is a piston rod with scale lines, which has a water inlet. On both sides of the column body, 6 water outlet angle valves are uniformly installed from top to bottom, the distance between 2 angle valves is $30 \mathrm{~cm}$. On the bottom of the column there is a ball valve for water inlet or leachate outlet. The structure of the soil column is shown in Figure 2a as follows.

Water seepage from top to bottom and water saturating from bottom to top are common methods of dynamic leaching. According to the condition of studying area, there is groundwater which saturated the backfill material at the bottom and there is also natural precipitation which seepages water from top to bottom. Hence we fill the column with backfill material to be a height of $180 \mathrm{~cm}$, and then on the top of backfill we filled natural soil with a height of $30 \mathrm{~cm}$. For dynamical leaching of backfill material we made the bottom two angle valves open and through the bottom ball valve to insure $30 \mathrm{~cm}$ backfill material always be submerged in water at column bottom, which simulated the effect of groundwater. From the top we simulated the natural precipitation to enter column through the piston rod according to local daily rainfall of 2017. The total experiments were implemented for 1 year, with simulated the real atmospheric precipitation of 2017. The testing period was from the beginning of January 2017 to the end of December 2017. Four soil columns was filled with designed backfill materials as coal gangue and fly ash proportions of 1:0.2, 1:0.4, 1:0.6, 1:0.8 were tested. The installation of the soil column dynamical leaching experiment is shown in Figure $2 \mathrm{~b}$ as follows. The tested samples of backfill material after leaching experiment were sampled about $10 \mathrm{~mm}$ above the simulated groundwater level, at the bottom of the soil column. 


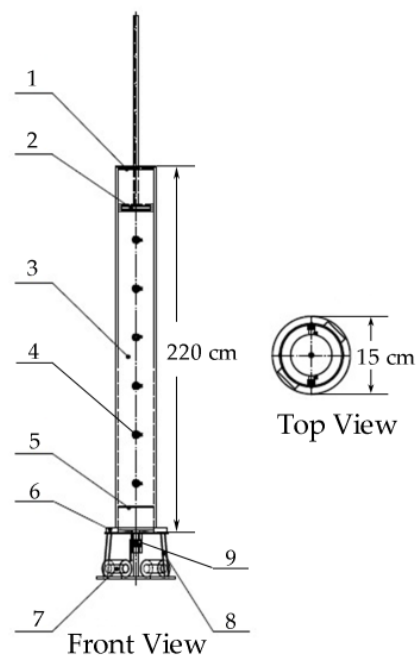

(a)

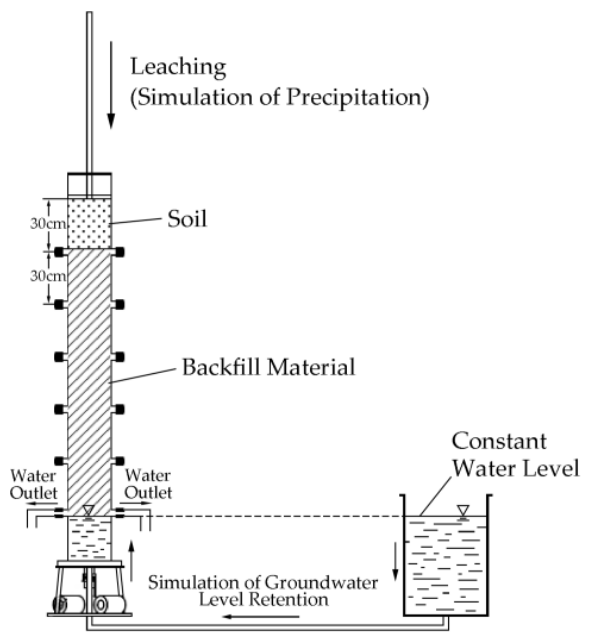

(b)

Figure 2. Testing Soil Column: (a) structure of soil column: 1-Testing soil column; 2-Piston rod assembly with graduated line; 3-Acrylic tube; 4-Angle valve; 5-Permeable tray; 6-Acrylic tube; 7-Balancing weight; 8-Base assembly; 9-Ball valve; (b) installation of soil column.

Coal gangues were sampled from the top, middle and bottom of the dump from Quantai-Qishan coalmine, sampled gangues were sieved according to the fractions of $10 \mathrm{~mm}, 15 \mathrm{~mm}, 20 \mathrm{~mm}, 25 \mathrm{~mm}$ and $30 \mathrm{~mm}$, respectively. The particle size distribution is shown in Figure 3 as follows.

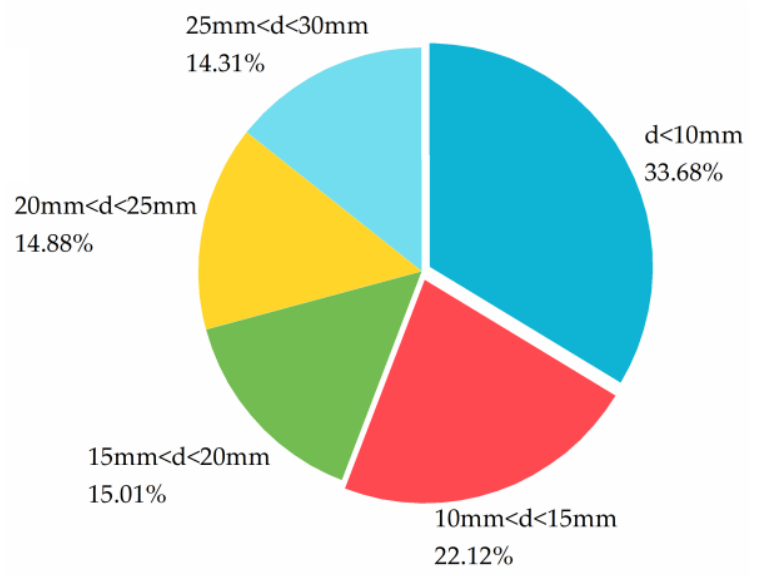

Figure 3. Coal gangue particle size distribution (mass).

The tested amount of backfill materials which were filled in each soil column are shown in Table 2 as follows:

Table 2. Coal gangue and fly ash filled in soil column. Unit: Kg.

\begin{tabular}{ccc}
\hline Mass Ratio/Material & Gangue & Fly Ash \\
\hline $1: 0.2$ & 25.00 & 5.00 \\
$1: 0.4$ & 22.43 & 8.97 \\
$1: 0.6$ & 20.75 & 12.45 \\
$1: 0.8$ & 19.22 & 15.37 \\
\hline
\end{tabular}

At the inlet and outlet of valves, steel wire screens and glass fiber with a thickness of $1 \mathrm{~cm}$ were used to prevent the runoff loss from fine material particles. Peristaltic pumps were used for water inlet according to the daily precipitation. 


\subsection{Sequential Extraction Analysis}

The laboratory equipment used in this study include: Insmark-IP126 type $\mathrm{pH}$ meter, Shanghai Lu Xiangyi TG1650-WS high-speed centrifuge, Changzhou Nuoji HY-5 rotary oscillator, Shanghai Haoyu FB224 automatic electronic analytical balance, Shanghai temperature control instrument factory DHG-9023A constant temperature drying oven, Crystal SY-1230 constant temperature water bath, $50 \mathrm{~mL}$ centrifuge tube, etc. Experimental reagents include: deionized water, ammonium acetate, hydroxylamine chloride, $30 \%$ hydrogen peroxide solution, nitric acid, sodium acetate, perchloric acid, etc.

The sequential extraction experiments were implemented as follows (modified according to our study purpose and previous studies [43]):

Crushing the backfill material samples before and after column leaching experiment until it could pass through the 200-mesh sieve. Then took $100 \mathrm{~g}$ of each crushed samples for analysis. For each analysis, $0.5 \mathrm{~g}$ sample was needed. The extraction processes are:

(1) Exchangeable state fraction: The room temperature was about $25^{\circ} \mathrm{C}$. We took $0.5 \mathrm{~g}$ (accuracy about $0.1 \mathrm{mg}$ ) of sample and place it in a $50 \mathrm{~mL}$ centrifuge tube, $10 \mathrm{~mL}$ of $1 \mathrm{~mol} / \mathrm{L}$ ammonium acetate were added and then adjust the $\mathrm{pH}$ value to 7 with nitric acid. Then we put it in a mechanical shaker for $2 \mathrm{~h}$ (HY-5 orbital shaker). The resulting solution was centrifuged at $3500 \mathrm{rpm}$ for $15 \mathrm{~min}$ (TG1650-WS high-speed centrifuge). The supernatant was then removed with a pipette and stored for analysis. Then the remaining residue in the centrifuge tube was washed with $20 \mathrm{~mL}$ deionized water and centrifuged at $3500 \mathrm{rpm}$ for $15 \mathrm{~min}$. (2) Carbonate binding state fraction: We put the remaining solids from the step (1) in a centrifuge tube, added $10 \mathrm{~mL}$ of $1 \mathrm{~mol} / \mathrm{L}$ sodium acetate, and then adjusted the $\mathrm{pH}$-value to 5 with nitric acid. Then, it was mixed in a mechanical shaker for $6 \mathrm{~h}$, and we put the solution to stand over one night. Then the solution was centrifuged at $3500 \mathrm{rpm}$ for $15 \mathrm{~min}$. The following steps were the same as in step (1). (3) Iron-manganese combined state fraction: $20 \mathrm{~mL}$ of $0.1 \mathrm{~mol} / \mathrm{L}$ ammonium hydrogen chloride were added to the remaining solids from step (2) in centrifuge tube, and then adjusted the $\mathrm{pH}$-value to 2 with nitric acid. Then we put it in a water bath which was set at $85^{\circ} \mathrm{C}$ for $6 \mathrm{~h}$ (SY-1230 constant temperature water bath kettle). During the water bath heating, we shook it occasionally. Then we let the solution to stand overnight and then were centrifuged at $3500 \mathrm{rpm}$ for $15 \mathrm{~min}$. The supernatant was removed and collected for further steps. The remaining solids were washed again as described in step (1). (4) Organic sulfide binding state fraction: To the remaining solids from step (3), $5 \mathrm{~mL}$ of $30 \%$ (mass) $\mathrm{H}_{2} \mathrm{O}_{2}$ were added and the mixture was stirred manually at room temperature for $1 \mathrm{~h}$, and then put it in a water bath which was set at $85^{\circ} \mathrm{C}$ for $1 \mathrm{~h}$ to reduce the volume fraction; then added $5 \mathrm{~mL}$ of $30 \%$ (mass) $\mathrm{H}_{2} \mathrm{O}_{2}$ solution again, and repeated the water bath step to evaporate and digest until they were nearly dry; after cooling, $25 \mathrm{~mL}$ of $1 \mathrm{~mol} / \mathrm{L}$ ammonium acetate were added; then adjusted the $\mathrm{pH}$-value to 2 with nitric acid, and mixed them in a mechanical shaker for $8 \mathrm{~h}$. The solution was then centrifuged at $3500 \mathrm{rpm}$ for $15 \mathrm{~min}$ and put it to stand overnight. The supernatant was then removed with a pipette into $50 \mathrm{~mL}$ volumetric flask and stored for analysis. The remaining steps were the same as step (1). (5) Residual state fraction: To the remaining solids from step (4), $6 \mathrm{~mL} 6 \mathrm{~mol} / \mathrm{L} \mathrm{HF}, 2 \mathrm{~mL} 6 \mathrm{~mol} / \mathrm{L} \mathrm{HNO}_{3}$ and $2 \mathrm{~mL} 6 \mathrm{~mol} / \mathrm{L} \mathrm{HClO}_{4}$ were added and allow the mixture stand overnight; then put it in a water bath for set at $90^{\circ} \mathrm{C}$ for $2 \mathrm{~h}$. The resulting solution was then centrifuged at $3500 \mathrm{rpm}$ for $15 \mathrm{~min}$, then the supernatant was removed with a pipette into $50 \mathrm{~mL}$ volumetric flask and stored for analysis.

In this research, if the tested backfill materials have high enough homogeneities, according to the digestion analysis, total content of a specific trace element includes above mentioned 4 fractions and the residual fraction. Then we could calculate with subtraction method, i.e., residual state $=$ total amount - (exchangeable state + carbonate binding state + iron-manganese combined state + organic sulfide binding state). 


\section{Results}

\subsection{Results of Sequential Extraction before Leaching}

As we have mentioned in Section 2.3, the studied trace metal concentrations in gangue, fly ash and four proportioned backfill materials are shown in Table 3 as follows.

Table 3. Digestion test results for all kinds of materials (before leaching). Unit: $\mathrm{mg} / \mathrm{kg}$.

\begin{tabular}{|c|c|c|c|c|c|c|c|}
\hline $\begin{array}{l}\text { Proportion/ } \\
\text { Element }\end{array}$ & $\mathrm{Cu}$ & $\mathrm{Zn}$ & $\mathrm{Pb}$ & $\mathrm{Cr}$ & $\mathrm{Cd}$ & Mn & $\mathbf{N i}$ \\
\hline $1: 0.2$ & $101.57 \pm 2.18$ & $243.02 \pm 4.33$ & $64.96 \pm 0.79$ & $218.62 \pm 1.79$ & $0.78 \pm 0.01$ & $1302.04 \pm 17.07$ & $94.23 \pm 1.80$ \\
\hline $1: 0.6$ & $133.24 \pm 1.95$ & $286.78 \pm 1.95$ & $74.32 \pm 1.53$ & $300.96 \pm 2.87$ & $0.98 \pm 0.04$ & $1015.53 \pm 21.50$ & $91.26 \pm 1.62$ \\
\hline $1: 0.8$ & $143.93 \pm 3.37$ & $301.54 \pm 3.19$ & $77.48 \pm 0.79$ & $328.75 \pm 3.11$ & $1.05 \pm 0.04$ & $1078.74 \pm 25.98$ & $90.26 \pm 0.94$ \\
\hline Full gangue & $76.63 \pm 1.12$ & $286.66 \pm 1.64$ & $57.57 \pm 0.97$ & $153.78 \pm 2.10$ & $0.63 \pm 0.03$ & $1433.10 \pm 26.83$ & $96.54 \pm 1.33$ \\
\hline
\end{tabular}

The $\mathrm{Cu}$ concentrations ranged from 76.63 to $231.62 \mathrm{mg} / \mathrm{kg}$, with the lowest value occurring in the full gangue and the highest value in the full fly ash. The Zn concentrations ranged from 243.02 to $422.57 \mathrm{mg} / \mathrm{kg}$, with the lowest value occurring in the 1:0.2 proportion and the highest value in the full fly ash. The $\mathrm{Pb}$ concentrations were in the range of 57.57 to $103.37 \mathrm{mg} / \mathrm{kg}$, the lowest value was found in the full gangue, and the highest value was in the full fly ash. The $\mathrm{Cr}$ concentrations ranged from 153.78 to $556.82 \mathrm{mg} / \mathrm{kg}$, with the lowest value occurred in the full gangue and the highest value in the full fly ash. The concentrations of Cd were in the range of 0.63 to $1.60 \mathrm{mg} / \mathrm{kg}$, the lowest value was found in the full gangue, and the highest value was found in full fly ash. The Mn concentrations ranged from 614.72 to $1433.10 \mathrm{mg} / \mathrm{kg}$, with the lowest value occurred in the full fly ash and the highest value in the full gangue. The Ni content ranged from 81.93 to $96.54 \mathrm{mg} / \mathrm{kg}$, with the lowest value occurred in the full fly ash and the highest value in the full gangue.

The tested results of full coal gangue and full fly ash are also shown in Table 3. To verify the homogeneity of backfill materials with 4 different proportions, we calculated their theoretical trace elements' content by using tested corresponding contents in full gangues and full fly ashes, as well as the proportions between used gangue and fly ash i.e., the 1:0.2, 1:0.4, 1:0.6 and 1:0.8. Then we measured the actual trace elements' content in different backfill materials also by using digestion analysis. Finally, we compared both results which are shown in Figure 4 as follows:

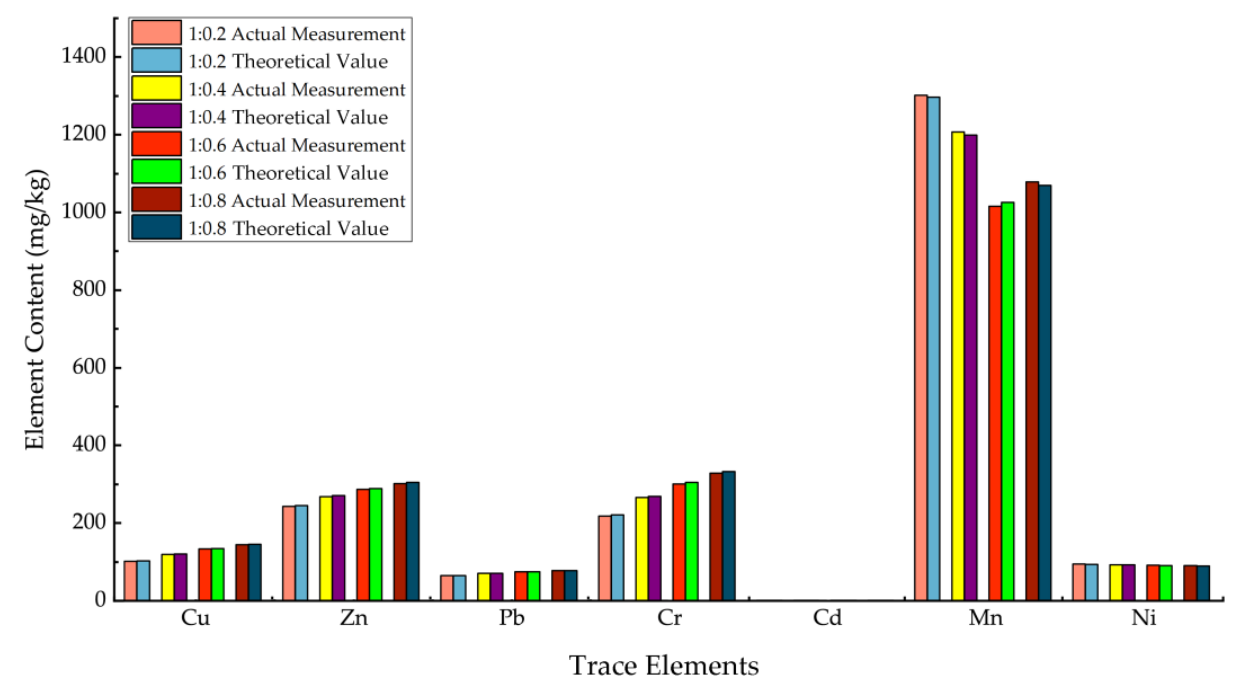

Figure 4. Comparison of the actual trace metal and theoretical concentrations in backfill material through digestion analysis (before leaching). (Cd: Actual measurement: $0.78 ; 0.9 ; 0.98 ; 1.05$. Theoretical value: $0.79 ; 0.91 ; 0.99 ; 1.06$.). 
Compared with the theoretical concentrations, the deviation between the measured values and theoretical value of tested trace metal contents in all 4 kinds of backfill materials were only about $1 \%$, which means that the raw material samples had high homogeneity and the results of the above-mentioned digestion analysis were reliable. The results could be used for further analysis together with sequential extraction.

The results of sequential extraction analysis are shown as follows from Tables 4-7.

Table 4. Results of sequential extraction of 1:0.2 samples. Unit: mg/kg.

\begin{tabular}{cccccccc}
\hline \multirow{2}{*}{ Occurrence State } & \multicolumn{7}{c}{ Trace Elements Contents } \\
\cline { 2 - 8 } & $\mathbf{C u}$ & $\mathbf{Z n}$ & $\mathbf{P b}$ & $\mathbf{C r}$ & $\mathbf{C d}$ & $\mathbf{M n}$ & $\mathbf{N i}$ \\
\hline Exchangeable state & 2.58 & 11.49 & 1.90 & 3.95 & 0.04 & 48.75 & 7.83 \\
Carbonate binding state & 23.34 & 17.02 & 0.88 & 4.87 & 0.23 & 33.78 & 11.73 \\
Iron-manganese combined state & 2.98 & 62.34 & 6.17 & 0.55 & 0.15 & 637.61 & 12.40 \\
Organic sulfide binding state & 48.02 & 147.60 & 5.11 & 8.59 & 0.36 & 325.01 & 29.62 \\
Residual state & 24.65 & 4.56 & 50.90 & 200.66 & 0.01 & 256.88 & 32.65 \\
\hline
\end{tabular}

Table 5. Results of sequential extraction of 1:0.4 samples. Unit: $\mathrm{mg} / \mathrm{kg}$.

\begin{tabular}{cccccccc}
\hline \multirow{2}{*}{ Occurrence State } & \multicolumn{7}{c}{ Trace Elements Contents } \\
\cline { 2 - 8 } & $\mathbf{C u}$ & $\mathbf{Z n}$ & $\mathbf{P b}$ & $\mathbf{C r}$ & $\mathbf{C d}$ & $\mathbf{M n}$ & $\mathbf{N i}$ \\
\hline Exchangeable state & 4.30 & 10.99 & 0.30 & 5.64 & 0.09 & 48.75 & 5.79 \\
Carbonate binding state & 37.89 & 11.32 & 1.07 & 4.35 & 0.18 & 86.46 & 13.40 \\
Iron-manganese combined state & 1.16 & 103.72 & 7.06 & 0.58 & 0.21 & 912.29 & 13.30 \\
Organic sulfide binding state & 48.19 & 106.73 & 20.08 & 9.73 & 0.36 & 45.40 & 25.13 \\
Residual state & 28.06 & 35.15 & 41.76 & 245.17 & 0.06 & 114.03 & 34.92 \\
\hline
\end{tabular}

Table 6. Results of sequential extraction of 1:0.6 samples. Unit: mg/kg.

\begin{tabular}{cccccccc}
\hline \multirow{2}{*}{ Occurrence State } & \multicolumn{7}{c}{ Trace Elements Contents } \\
\cline { 2 - 8 } & $\mathbf{C u}$ & $\mathbf{Z n}$ & $\mathbf{P b}$ & $\mathbf{C r}$ & $\mathbf{C d}$ & $\mathbf{M n}$ & $\mathbf{N i}$ \\
\hline Exchangeable state & 5.62 & 11.48 & 0.44 & 5.49 & 0.12 & 32.54 & 7.05 \\
Carbonate binding state & 55.62 & 12.24 & 0.90 & 5.21 & 0.11 & 66.41 & 13.89 \\
Iron-manganese combined state & 0.99 & 97.20 & 6.00 & 0.50 & 0.41 & 699.11 & 9.53 \\
Organic sulfide binding state & 45.43 & 96.78 & 21.84 & 10.42 & 0.22 & 42.36 & 24.19 \\
Residual state & 25.58 & 69.08 & 45.15 & 279.34 & 0.12 & 175.11 & 36.60 \\
\hline
\end{tabular}

Table 7. Results of sequential extraction of 1:0.8 samples. Unit: mg/kg.

\begin{tabular}{cccccccc}
\hline Occurrence State & \multicolumn{7}{c}{ Trace Elements Contents } \\
\cline { 2 - 8 } & $\mathbf{C u}$ & $\mathbf{Z n}$ & $\mathbf{P b}$ & $\mathbf{C r}$ & $\mathbf{C d}$ & $\mathbf{M n}$ & $\mathbf{N i}$ \\
\hline Exchangeable state & 5.58 & 11.52 & 0.31 & 7.02 & 0.17 & 47.96 & 6.33 \\
Carbonate binding state & 55.92 & 11.78 & 0.81 & 3.97 & 0.24 & 51.77 & 9.45 \\
Iron-manganese combined state & 0.74 & 46.22 & 3.87 & 0.37 & 0.16 & 692.29 & 9.53 \\
Organic sulfide binding state & 44.33 & 116.41 & 19.00 & 9.52 & 0.35 & 37.90 & 21.10 \\
Residual state & 37.35 & 115.62 & 53.49 & 307.86 & 0.13 & 248.82 & 43.85 \\
\hline
\end{tabular}

It could be deduced that for the tested trace elements, the residue states and the organic sulfide binding states were accounted as the main parts among all occurrence states, over $65 \%$ in mass. In which the sum of these two states of 1:0.2 proportion was $68 \%$, in 1:0.4 proportion was $61 \%$, in 1:0.6 proportion was $60 \%$, and in 1:0.8 proportion was $67 \%$. In addition, the sum of these two states of full gangue was $65 \%$, in full fly ash was $72 \%$. The two active states, i.e., the exchangeable state and the carbonate binding state of tested trace metals had very low proportions in mass, accounted for $4.97 \%$ and $11.01 \%$, respectively. Due to the low concentration of these two active states, the trace 
metal elements in the backfill materials had only limited risks to the environment. The occurrence states of $\mathrm{Cr}$ show that, $\mathrm{Cr}$ was mainly in the residue state with a mean value nearly $93 \%$. The lowest value of $91 \%$ occurred in the 1:0.2 proportion, and the highest value of $94 \%$ appeared in the 1:0.8 proportion. The proportion of its residual state increases with the proportion of fly ash. The occurrence states of $\mathrm{Cd}$ show that the iron-manganese combined state and the organic sulfide binding state were accounted for more than $50 \%$ of all kinds of materials, the average proportion of the two states was up to $55 \%$. Both the exchangeable state and the residue state increased with an increasing of fly ash proportion. The iron-manganese combined state fell sharply between 1:0.6 and 1:0.8 proportions. The carbonate binding state and the organic sulfide binding state decreased as the proportion of fly ash increased, but they also increased sharply between proportions 1:0.6 and 1:0.8. Probably there is a certain inflection point between the proportions of 1:0.6 and 1:0.8. The occurrence states of $\mathrm{Cu}$ shows that the sum of the carbonate binding state, the organic sulfide binding state and the residual state in the respective proportions occupied about $94 \%$ in mass, mainly in the organic sulfide binding state, followed by carbonate binding state and residue state. Due to strong ability of $\mathrm{Cu}$ in forming complex, the resulted chelates had strong stability. The occurrence states of Mn element shows that the iron-manganese combined state was dominant among all proportions, with a mean value approximately $62 \%$, then followed by residue state and organic sulfide binding state. Exchangeable and carbonate binding states were very few, with a total proportion less than $10 \%$. The occurrence state of Ni element shows that among all 4 kinds of materials, the organic sulfide binding state and residual state were dominate, with a sum about $68 \%$ in mass. The proportions of exchangeable, carbonate binding, and iron-manganese combined states were low, only $8 \%, 13 \%$, and $12 \%$ in mass, respectively. The occurrence state of $\mathrm{Pb}$ shows that among all 4 kinds of materials, residue states were dominant, with an average proportion of $70 \%$ in mass, followed by $19 \%$ of organic sulfide binding state. Exchangeable and carbonate binding states accounted for only about $1 \%$. The occurrence states of $\mathrm{Zn}$ element shows that in each kind of material, organic sulfide binding states were dominant, totally accounted for about $39 \%$. Followed by iron-manganese combined state and residue state, each accounted for $26 \%$. The residue state increases with the content of fly ash.

The experimental results show that seven trace metals which were studied appeared all five occurrence states. For $\mathrm{Cr}$ and $\mathrm{Pb}$, residual state occupied the main part; for $\mathrm{Mn}, \mathrm{Cd}$ and $\mathrm{Zn}$, iron-manganese combined state took the main part; and for $\mathrm{Cu}$, carbonate binding state accounted for the main part; for $\mathrm{Ni}$, organic sulfide binding state and residual state occupied the main part. The harmful trace metal elements, which are mainly composed of residual state and organic sulfide binding state, have limited risk to environment.

\subsection{Results of Sequential Extraction after Leaching}

Digestion analyses after soil column leaching experiments were implemented on the backfill materials including proportions of 1:0.2, 1:0.4, 1:0.6, and 1:0.8. The results are shown in Table 8.

Table 8. Digestion results of 4 kinds of materials (after leaching). Unit: $\mathrm{mg} / \mathrm{kg}$.

\begin{tabular}{cccccccc}
\hline $\begin{array}{c}\text { Proportion/ } \\
\text { Element }\end{array}$ & $\mathbf{C u}$ & $\mathbf{Z n}$ & $\mathbf{P b}$ & $\mathbf{C r}$ & $\mathbf{C d}$ & $\mathbf{M n}$ & $\mathbf{N i}$ \\
\hline $1: 0.2$ & $273.51 \pm 4.20$ & $665.45 \pm 6.84$ & $112.76 \pm 4.86$ & $243.16 \pm 4.10$ & $1.49 \pm 0.02$ & $656.58 \pm 6.62$ & $95.31 \pm 1.76$ \\
$1: 0.4$ & $298.85 \pm 3.82$ & $796.74 \pm 8.20$ & $117.38 \pm 2.04$ & $268.47 \pm 3.80$ & $1.49 \pm 0.04$ & $592.08 \pm 7.56$ & $91.19 \pm 0.59$ \\
$1: 0.6$ & $172.49 \pm 3.97$ & $520.11 \pm 9.87$ & $98.79 \pm 1.06$ & $258.85 \pm 0.64$ & $1.21 \pm 0.02$ & $922.77 \pm 13.12$ & $85.56 \pm 1.27$ \\
$1: 0.8$ & $259.16 \pm 1.64$ & $675.23 \pm 6.15$ & $112.26 \pm 2.45$ & $271.05 \pm 2.58$ & $1.70 \pm 0.05$ & $613.2 \pm 6.23$ & $92.25 \pm 2.04$ \\
\hline
\end{tabular}

$\mathrm{Cu}$ concentrations ranged from 172.49 to $298.85 \mathrm{mg} / \mathrm{kg}$, with the lowest value occurred in 1:0.6 proportion and the highest value in 1:0.4 proportion. Zn concentrations ranged from 520.11 to $796.74 \mathrm{mg} / \mathrm{kg}$, with the lowest value occurring in 1:0.6 proportion and the highest value in 1:0.4 proportion. $\mathrm{Pb}$ concentrations were in the range of 98.97 to $117.38 \mathrm{mg} / \mathrm{kg}$, the lowest value was found in 1:0.6 proportion, and the highest value was in 1:0.4 proportion. Cr concentrations ranged from 
243.16 to $271.05 \mathrm{mg} / \mathrm{kg}$, with the lowest value occurred in 1:0.2 proportion and the highest value in 1:0.8 proportion. The concentrations of $\mathrm{Cd}$ were in the range of 1.21 to $1.70 \mathrm{mg} / \mathrm{kg}$, the lowest value was found in 1:0.6 proportion, and the highest value was found in 1:0.8 proportion. Mn concentrations ranged from 592.08 to $922.77 \mathrm{mg} / \mathrm{kg}$, with the lowest value occurred in 1:0.4 proportion and the highest value in 1:0.6 proportion. Ni contents ranged from 85.56 to $95.31 \mathrm{mg} / \mathrm{kg}$, with the lowest value occurred in 1:0.6 proportion and the highest value in 1:0.2 proportion.

Results of sequential extraction experiments after leaching are shown in Tables 9-12 as follows.

Table 9. Results of sequential extraction of 1:0.2 samples (after leaching). Unit: $\mathrm{mg} / \mathrm{kg}$.

\begin{tabular}{cccccccc}
\hline \multirow{2}{*}{ Occurrence State } & \multicolumn{7}{c}{ Trace Elements Contents } \\
\cline { 2 - 8 } & $\mathbf{C u}$ & $\mathbf{Z n}$ & $\mathbf{P b}$ & $\mathbf{C r}$ & $\mathbf{C d}$ & $\mathbf{M n}$ & $\mathbf{N i}$ \\
\hline Exchangeable state & 31.40 & 8.98 & 0.19 & 4.43 & 0.09 & 30.53 & 2.79 \\
Carbonate binding state & 5.38 & 59.74 & 0.23 & 0.83 & 0.12 & 150.75 & 2.29 \\
Iron-manganese combined state & 29.43 & 2.50 & 0.12 & 2.50 & 0.27 & 90.00 & 6.26 \\
Organic sulfide binding state & 54.14 & 102.65 & 10.98 & 8.16 & 0.13 & 92.28 & 9.24 \\
Residual state & 153.16 & 491.57 & 101.24 & 227.25 & 0.88 & 293.03 & 74.73 \\
\hline
\end{tabular}

Table 10. Results of sequential extraction of 1:0.4 samples (after leaching). Unit: $\mathrm{mg} / \mathrm{kg}$.

\begin{tabular}{cccccccc}
\hline \multirow{2}{*}{ Occurrence State } & \multicolumn{7}{c}{ Trace Elements Contents } \\
\cline { 2 - 8 } & $\mathbf{C u}$ & $\mathbf{Z n}$ & $\mathbf{P b}$ & $\mathbf{C r}$ & $\mathbf{C d}$ & $\mathbf{M n}$ & $\mathbf{N i}$ \\
\hline Exchangeable state & 19.55 & 2.50 & 0.12 & 4.48 & 0.09 & 25.60 & 2.47 \\
Carbonate binding state & 2.71 & 66.06 & 0.35 & 0.36 & 0.20 & 295.56 & 4.71 \\
Iron-manganese combined state & 43.81 & 2.09 & 0.04 & 1.81 & 0.23 & 84.05 & 5.48 \\
Organic sulfide binding state & 48.78 & 82.81 & 8.04 & 9.44 & 0.13 & 59.64 & 8.63 \\
Residual state & 184.00 & 643.28 & 108.83 & 252.38 & 0.85 & 127.24 & 69.90 \\
\hline
\end{tabular}

Table 11. Results of sequential extraction of 1:0.6 samples (after leaching). Unit: $\mathrm{mg} / \mathrm{kg}$.

\begin{tabular}{cccccccc}
\hline \multirow{2}{*}{ Occurrence State } & \multicolumn{7}{c}{ Trace Elements Contents } \\
\cline { 2 - 8 } & $\mathbf{C u}$ & $\mathbf{Z n}$ & $\mathbf{P b}$ & $\mathbf{C r}$ & $\mathbf{C d}$ & $\mathbf{M n}$ & $\mathbf{N i}$ \\
\hline Exchangeable state & 18.13 & 4.16 & 0.09 & 4.43 & 0.09 & 35.04 & 3.53 \\
Carbonate binding state & 5.00 & 79.64 & 1.92 & 0.38 & 0.13 & 278.52 & 6.80 \\
Iron-manganese combined state & 60.79 & 1.55 & 0.14 & 1.24 & 0.12 & 112.65 & 3.57 \\
Organic sulfide binding state & 41.28 & 98.46 & 18.69 & 8.22 & 0.12 & 74.77 & 12.70 \\
Residual state & 47.29 & 336.31 & 77.97 & 244.58 & 0.76 & 421.80 & 58.96 \\
\hline
\end{tabular}

Table 12. Results of sequential extraction of 1:0.8 samples (after leaching). Unit: $\mathrm{mg} / \mathrm{kg}$.

\begin{tabular}{cccccccc}
\hline \multirow{2}{*}{ Occurrence State } & \multicolumn{7}{c}{ Trace Elements Contents } \\
\cline { 2 - 8 } & $\mathbf{C u}$ & $\mathbf{Z n}$ & $\mathbf{P b}$ & $\mathbf{C r}$ & $\mathbf{C d}$ & $\mathbf{M n}$ & $\mathbf{N i}$ \\
\hline Exchangeable state & 20.26 & 5.30 & 0.09 & 5.61 & 0.15 & 35.35 & 4.13 \\
Carbonate binding state & 4.49 & 69.57 & 0.22 & 0.29 & 0.21 & 234.02 & 5.15 \\
Iron-manganese combined state & 76.97 & 2.31 & 0.16 & 1.19 & 0.13 & 86.91 & 2.77 \\
Organic sulfide binding state & 44.01 & 88.90 & 14.21 & 9.91 & 0.15 & 73.10 & 6.95 \\
Residual state & 113.43 & 509.15 & 97.59 & 254.06 & 1.06 & 183.82 & 73.25 \\
\hline
\end{tabular}

Among all 4 kinds of tested materials, after leaching the residual state and the Organic sulfide binding state still accounted for the major parts of the total occurrence state, and the sum of these two states exceeded $78 \%$ in mass. In addition, in 1:0.2 proportion the sum of these two states was $82 \%$ in mass, the sum of these two states in 1:0.4 proportion was $79 \%$, in 1:0.6 proportion was $77 \%$, and in 1:0.8 proportion was $78 \%$. Compared with the materials before leaching, the sum of the residual state and the organic sulfide binding state among the tested trace metals increased with an average 
of $23 \%$. The exchangeable state and carbonate binding state were kept in low level, accounted for $3.89 \%$ and $9.30 \%$, respectively, and there was a slight decrease compared with the backfill material before leaching. After leaching the migration ability of harmful trace metals in the backfill material had been further restricted to a certain extent. After leaching the total amount of $\mathrm{Cu}$ and $\mathrm{Pb}$ were significantly higher than that before leaching. Especially $\mathrm{Cu}$ increased by maximum of 169\% in 1:0.2 proportion. The total amount of Ni element also increased a little after leaching, varied between $1 \%$ and $6 \%$. After leaching the total amount of $\mathrm{Zn}$ was also higher than before, with an average increase rate up to $140 \%$. After leaching the total amount of $\mathrm{Cr}$ in 1:0.2 proportion increased by $11 \%$ compared to before leaching. After leaching the total amount of $\mathrm{Cd}$ was significantly higher than that before leaching, with average increasing of $61 \%$. After leaching the total amount of Mn was significantly reduced compared to that before leaching. The average decline rate achieved $39 \%$.

The increasing of total amount of tested trace metals shows that under the driving of hydrodynamic effect by leaching. The overall migration of trace metal was to be transported deeper inside the backfill material, i.e., to go deeper inside the reclaimed subsidence area. Meanwhile the occurrence states of the tested metal elements had become more and more stable to against hydro-migration effect.

\subsection{Sequential Extraction Analysis Before and After Soil Column Leaching}

Before and after soil column leaching experiments, the trace metals' occurrence states of $\mathrm{Cd}, \mathrm{Cr}$, $\mathrm{Cu}, \mathrm{Mn}, \mathrm{Ni}, \mathrm{Pb}$ and $\mathrm{Zn}$ were analyzed, which are shown in Tables 13-19, as well as Figures 5-11 as follows, respectively.

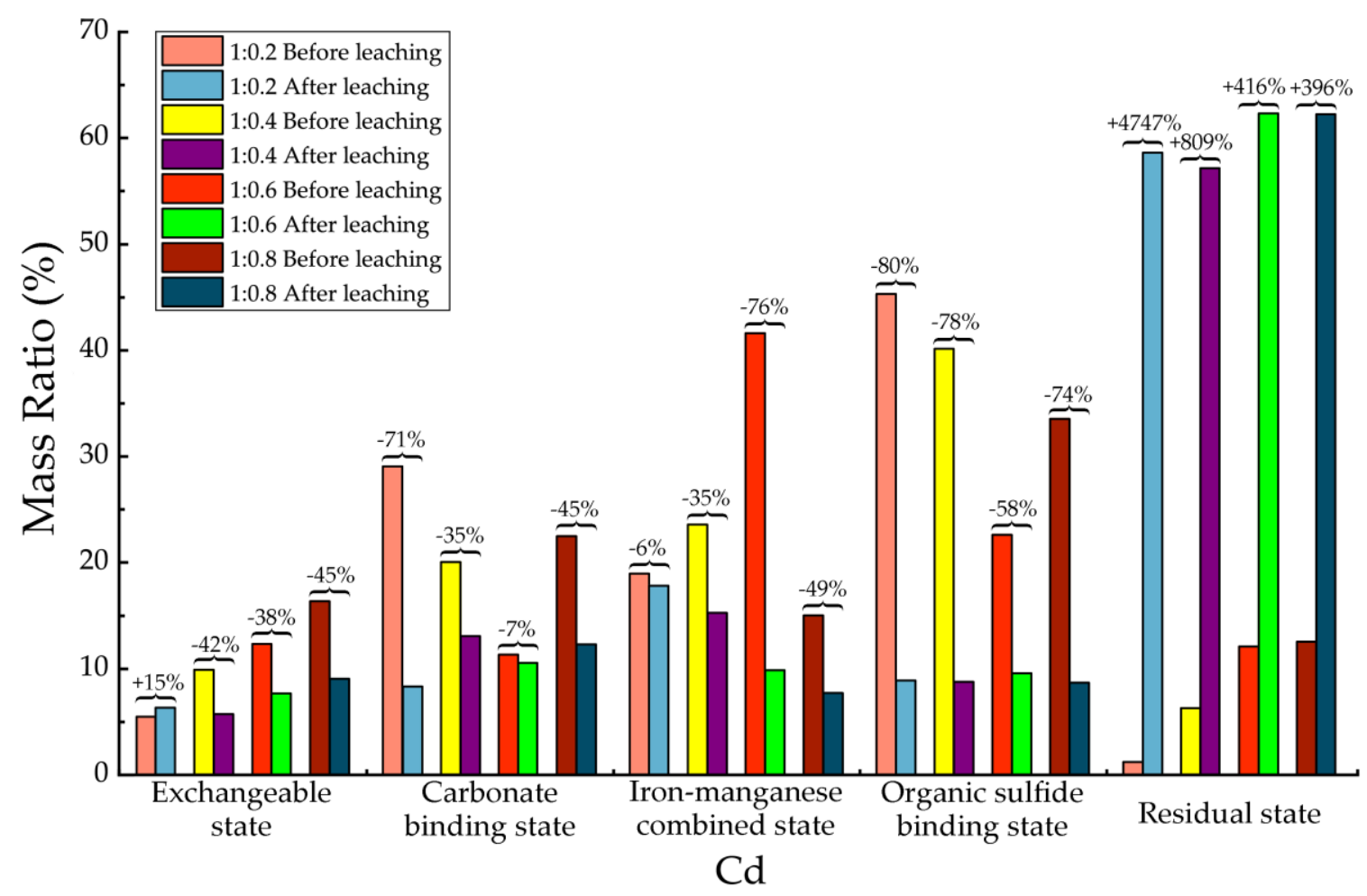

Figure 5. Sequential extraction of $\mathrm{Cd}$ before and after leaching in different occurrence states.

According to Figure 5 and Table 13, after leaching the most significant change of Cd was the increasing of residue state concentration, which up to $1600 \%$ on average among all 4 proportions. In addition, meanwhile, other occurrence states' decreased significantly. The concentration of exchangeable state decreased about $38-42 \%$ among all proportions except its concentration of 1:0.2 proportion, which was a little bit higher than that before leaching, which could due to experimental 
errors. The concentration decreasing of carbonate binding Cd was $7-71 \%$ among all proportions. The highest decreasing was found in 1:0.2 proportion. The concentration decreasing of iron-manganese combined $\mathrm{Cd}$ was $6-76 \%$. In addition, the concentration decreasing of organic sulfide-binding $\mathrm{Cd}$ ranged from $58 \%$ to $80 \%$. From the results, it could be deduced that after leaching, the occurrence states of $\mathrm{Cd}$ had become much more inactive. Its migration abilities in all states were completely decreased and the residual state were significantly increased to a large extent. Furthermore, considering the absolute amount of $\mathrm{Cd}$ in backfill material was very low, we could make the conclusion that the $\mathrm{Cd}$ has nearly no potential of environmental risks.

Table 13. Mass ratio variation of $\mathrm{Cd}$ occurrence states before and after leaching.

\begin{tabular}{ccccc}
\hline State of Occurrence/Proportion & $\mathbf{1 : 0 . 2}$ & $\mathbf{1 : 0 . 4}$ & $\mathbf{1 : 0 . 6}$ & $\mathbf{1 : 0 . 8}$ \\
\hline Exchangeable state & $15 \%$ & $-42 \%$ & $-38 \%$ & $-45 \%$ \\
Carbonate binding state & $-71 \%$ & $-35 \%$ & $-7 \%$ & $-45 \%$ \\
Iron-manganese combined state & $-6 \%$ & $-35 \%$ & $-76 \%$ & $-49 \%$ \\
Organic sulfide binding state & $-80 \%$ & $-78 \%$ & $-58 \%$ & $-74 \%$ \\
Residual state & $4747 \%$ & $809 \%$ & $416 \%$ & $396 \%$ \\
\hline
\end{tabular}

According to Figure 6 and Table 14, there was no significant change in the exchangeable state, organic sulfide binding state and residual state of $\mathrm{Cr}$ before and after leaching. Their variations in concentration ranged from $0 \%$ to $26 \%$. The most significant change happened in iron-manganese combined state of $\mathrm{Cr}$, with average increasing among all 4 proportions about $250 \%$ after leaching. Then followed by the carbonate binding state, whose concentration decreased by more than $85 \%$ after leaching. The results had demonstrated that in backfill materials, most of the $\mathrm{Cr}$ element existed as residual state. The Exchangeable state, carbonate binding state, iron-manganese combined state and organic sulfide binding state occupied only very few proportion, and the acting of hydrodynamic leaching has very limited effect on transformation of Cr's occurrence state, only significant effects on transformation of carbonate binding state to iron-manganese combined state, which had also decreased the migration ability of $\mathrm{Cr}$ to a certain extent.

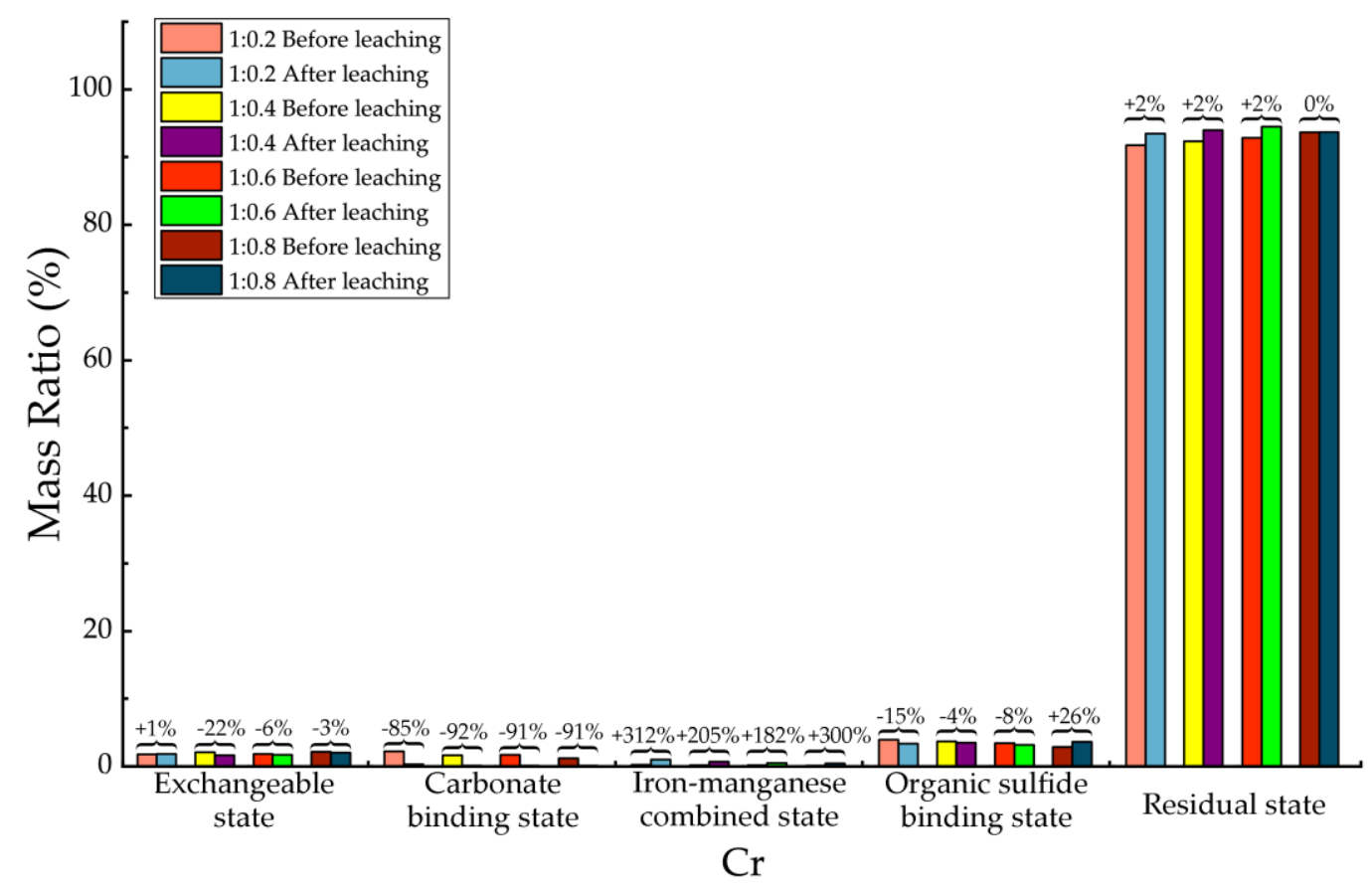

Figure 6. Sequential extraction of $\mathrm{Cr}$ before and after leaching in different occurrence states. 
Table 14. Mass ratio variation of Cr occurrence states before and after leaching.

\begin{tabular}{ccccc}
\hline State of Occurrence/Proportion & $\mathbf{1 : 0 . 2}$ & $\mathbf{1 : 0 . 4}$ & $\mathbf{1 : 0 . 6}$ & $\mathbf{1 : 0 . 8}$ \\
\hline Exchangeable state & $1 \%$ & $-22 \%$ & $-6 \%$ & $-3 \%$ \\
Carbonate binding state & $-85 \%$ & $-92 \%$ & $-91 \%$ & $-91 \%$ \\
Iron-manganese combined state & $312 \%$ & $205 \%$ & $182 \%$ & $300 \%$ \\
Organic sulfide binding state & $-15 \%$ & $-4 \%$ & $-8 \%$ & $26 \%$ \\
Residual state & $2 \%$ & $2 \%$ & $2 \%$ & $0 \%$ \\
\hline
\end{tabular}

According to Figure 7 and Table 15, after leaching the concentrations of the exchangeable state, the iron-manganese combined state, and the residual state of $\mathrm{Cu}$ were significantly increased. Especially the average increasing of iron-manganese combined states was up to $3000 \%$, in which the maximum increasing was up to $5612 \%$ in 1:0.8 proportion. The exchangeable state increased with an average of $171 \%$ after leaching, with a maximum value of $352 \%$ in 1:0.2 proportion. After leaching the average increasing of residual state was 101\%, with the highest value in 1:0.4 proportion of $162 \%$. The concentration of carbonate binding state and organic sulfide binding state in all 4 proportions were significantly reduced after leaching. The carbonate binding state decreased with an average of $94 \%$. In addition, the concentration of organic sulfide binding state decreased averagely about $48 \%$. For Cu element in backfill material, most of them were transformed from a carbonate binding state to iron-manganese combined state, as well as from organic sulfide binding state to residual state. Although the exchangeable state of $\mathrm{Cu}$ was also increased to a certain extent, consider the absolute quantity among all occurrence states, the overall migration activity of $\mathrm{Cu}$ element had been significantly restricted.

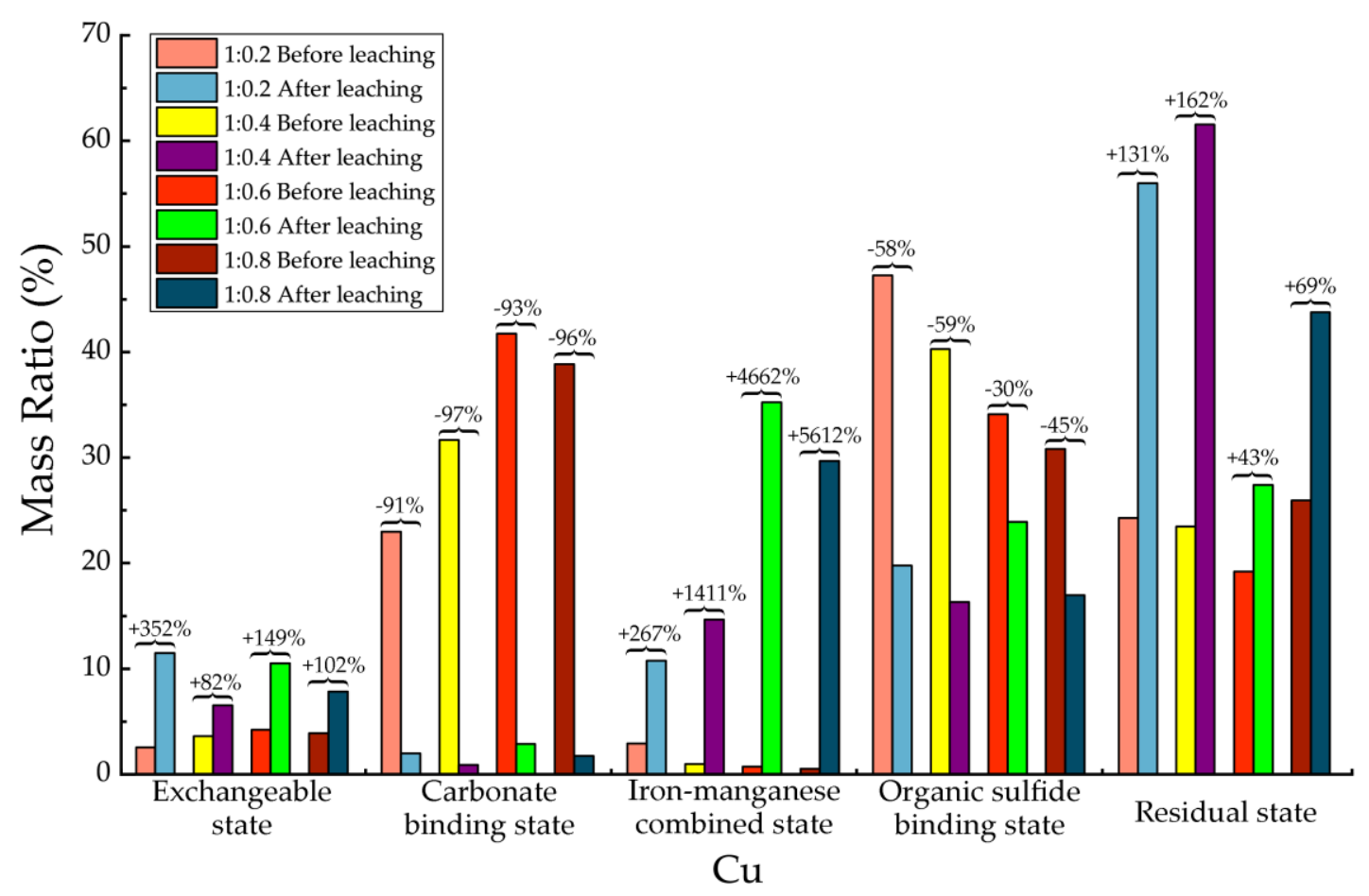

Figure 7. Sequential extraction of $\mathrm{Cu}$ before and after leaching in different occurrence states. 
Table 15. Mass ratio variation of $\mathrm{Cu}$ occurrence states before and after leaching.

\begin{tabular}{ccccc}
\hline State of Occurrence/Proportion & $\mathbf{1 : 0 . 2}$ & $\mathbf{1 : 0 . 4}$ & $\mathbf{1 : 0 . 6}$ & $\mathbf{1 : 0 . 8}$ \\
\hline Exchangeable state & $352 \%$ & $82 \%$ & $149 \%$ & $102 \%$ \\
Carbonate binding state & $-91 \%$ & $-97 \%$ & $-93 \%$ & $-96 \%$ \\
Iron-manganese combined state & $267 \%$ & $1411 \%$ & $4662 \%$ & $5612 \%$ \\
Organic sulfide binding state & $-58 \%$ & $-59 \%$ & $-30 \%$ & $-45 \%$ \\
Residual state & $131 \%$ & $162 \%$ & $43 \%$ & $69 \%$ \\
\hline
\end{tabular}

According to Figure 8 and Table 16, after leaching the proportions of carbonate binding state, residue state, and exchangeable state of the $\mathrm{Mn}$ increased. The carbonate binding state was obviously increased than before leaching, with an average of $607 \%$. The increase of residual state was relatively higher than that before leaching, with an average of $112 \%$ t. For organic sulfide binding state, its content in 1:0.2 proportion decreased than before leaching, but in the other proportions it increased. For iron-manganese combined state, its content in each proportion decreased significantly than before leaching, with an average decrease of $78 \%$, from which the maximum decrease was $82 \%$ in 1:0.6 material, then $72 \%$ in 1:0.2 material.

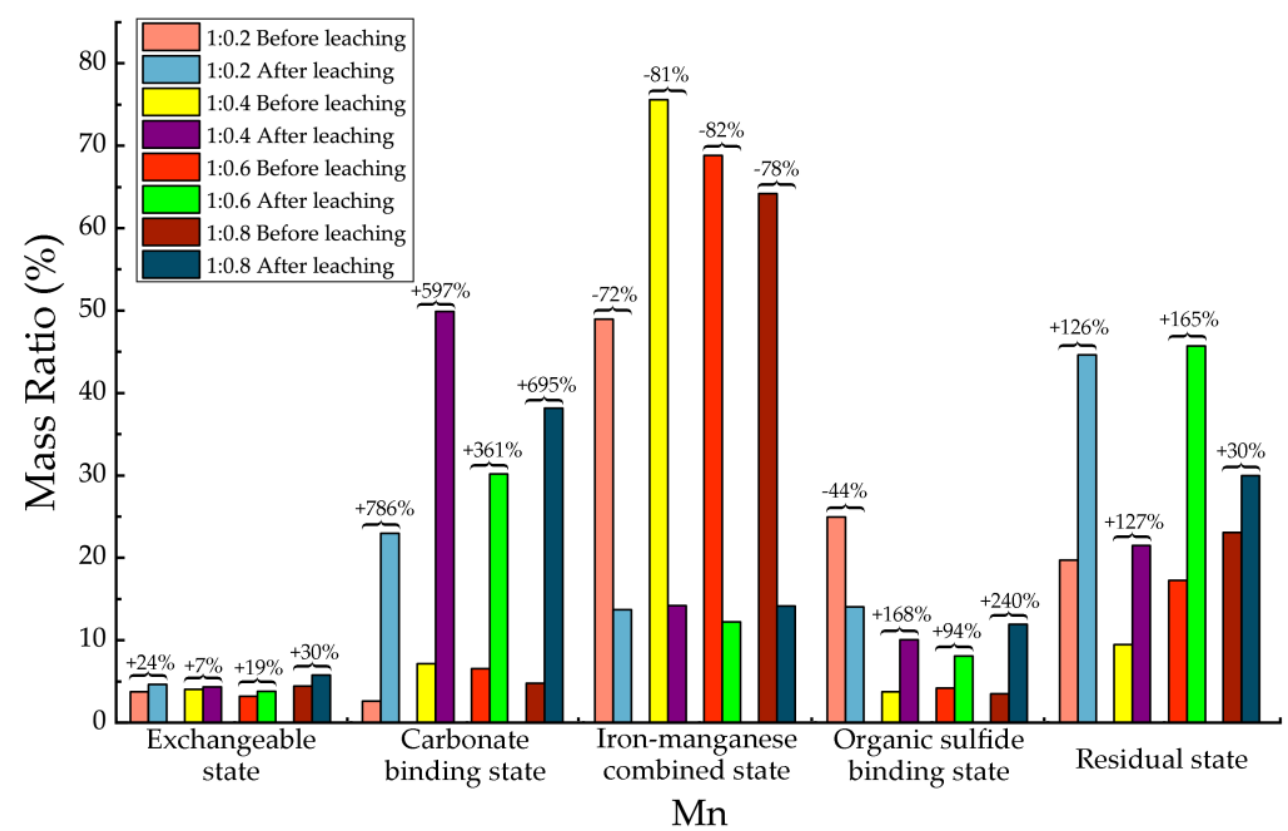

Figure 8. Sequential extraction of Mn before and after leaching in different occurrence states.

Table 16. Mass ratio variation of Mn occurrence states before and after leaching.

\begin{tabular}{ccccc}
\hline State of Occurrence/Proportion & $\mathbf{1 : 0 . 2}$ & $\mathbf{1 : 0 . 4}$ & $\mathbf{1 : 0 . 6}$ & $\mathbf{1 : 0 . 8}$ \\
\hline Exchangeable state & $24 \%$ & $7 \%$ & $19 \%$ & $30 \%$ \\
Carbonate binding state & $786 \%$ & $597 \%$ & $361 \%$ & $695 \%$ \\
Iron-manganese combined state & $-72 \%$ & $-81 \%$ & $-82 \%$ & $-78 \%$ \\
Organic sulfide binding state & $-44 \%$ & $168 \%$ & $94 \%$ & $240 \%$ \\
Residual state & $126 \%$ & $127 \%$ & $165 \%$ & $30 \%$ \\
\hline
\end{tabular}

According to Figure 9 and Table 17, for Ni element, after leaching only the concentration of residue state increased significantly. The concentrations of other states decreased. Among all 4 kinds of materials, the average increasing of residual state was $91 \%$ in mass than before leaching. The exchangeable state decreased about $36 \%$ to $65 \%$ after leaching, and the carbonate binding state decreased $47-81 \%$. The decreasing of iron-manganese combined state ranged from $50 \%$ to $72 \%$ and the organic sulfide binding state decreased $44-69 \%$. After soil column leaching, the exchangeable 
state, carbonate binding state, iron-manganese combined state as well as the organic sulfide binding state of $\mathrm{Ni}$ in backfill material were significantly decreased and the residual state increased greatly, which demonstrated that the potential of $\mathrm{Ni}$ transportation into ambient environment had been strictly decreased.

Table 17. Mass ratio variation of Ni occurrence states before and after leaching.

\begin{tabular}{ccccc}
\hline State of Occurrence/Proportion & $\mathbf{1 : 0 . 2}$ & $\mathbf{1 : 0 . 4}$ & $\mathbf{1 : 0 . 6}$ & $\mathbf{1 : 0 . 8}$ \\
\hline Exchangeable state & $-65 \%$ & $-57 \%$ & $-47 \%$ & $-36 \%$ \\
Carbonate binding state & $-81 \%$ & $-64 \%$ & $-48 \%$ & $-47 \%$ \\
Iron-manganese combined state & $-50 \%$ & $-58 \%$ & $-60 \%$ & $-72 \%$ \\
Organic sulfide binding state & $-69 \%$ & $-65 \%$ & $-44 \%$ & $-68 \%$ \\
Residual state & $126 \%$ & $103 \%$ & $72 \%$ & $63 \%$ \\
\hline
\end{tabular}

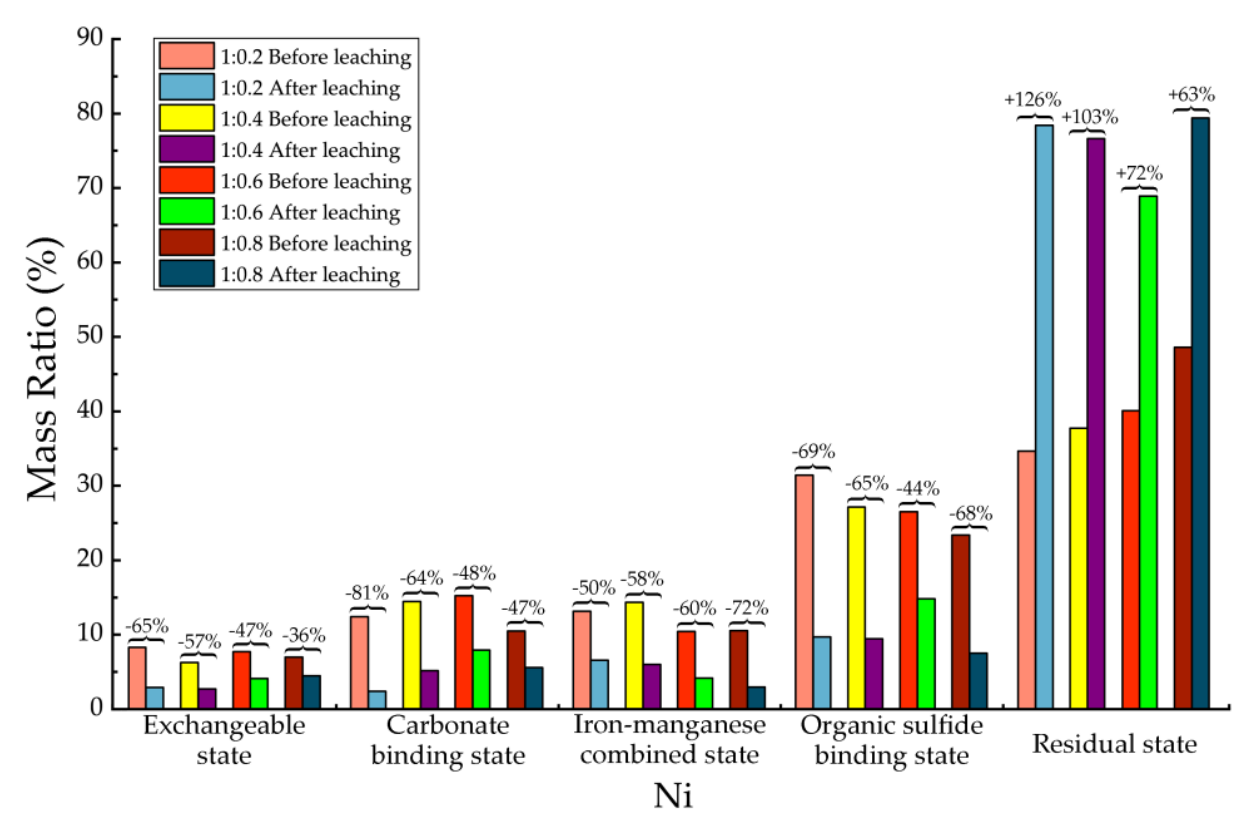

Figure 9. Sequential extraction of $\mathrm{Ni}$ before and after leaching in different occurrence states.

According to Figure 10 and Table 18, for Pb element, after leaching there was almost only the residual state increased significantly. The concentration of other 4 states decreased, among which the exchangeable state decreased about 77-94\% in mass. The decreasing of carbonate binding state ranged from $80 \%$ to $85 \%$, but for the proportion of $1: 0.6$ there was an increasing of $60 \%$ which is unreasonable. Consider the absolute amount of $\mathrm{Pb}$ carbonate binding state, the reason might due to experimental error. The decreasing of iron-manganese combined state ranged around $99 \%$. The decreasing of organic sulfides states ranged from $36 \%$ to $78 \%$, and there was also a small increasing of $24 \%$ in the proportion of 1:0.2, which had no influence the overall trend of decreasing. The experimental results demonstrated that after leaching $\mathrm{Pb}$ element exited in backfill material mainly in residual state and a little bit organic sulfide binding state, the activity of $\mathrm{Pb}$ element in migration from backfill material to ambient environment had been greatly restricted. 


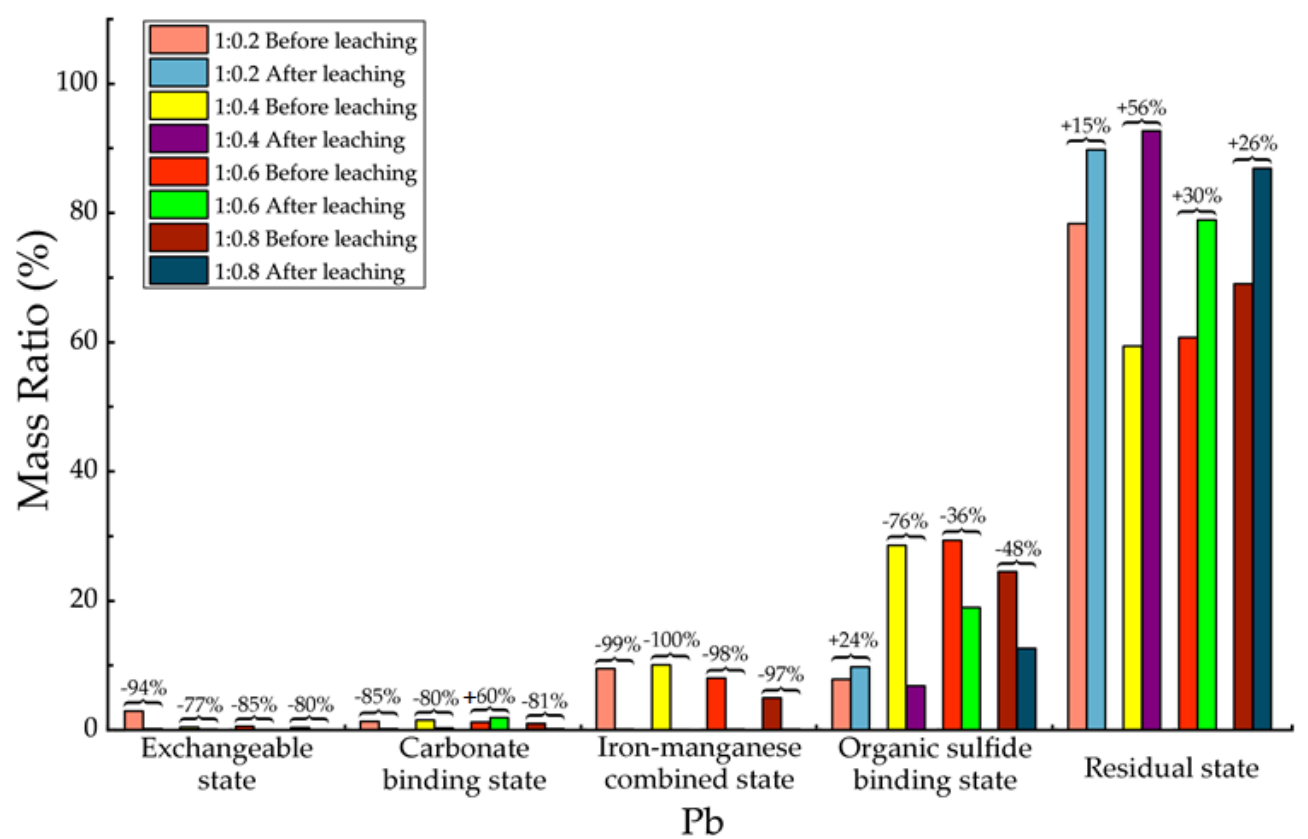

Figure 10. Sequential extraction of $\mathrm{Pb}$ before and after leaching in different occurrence states.

Table 18. Mass ratio variation of $\mathrm{Pb}$ occurrence states before and after leaching.

\begin{tabular}{ccccc}
\hline State of Occurrence/Proportion & $\mathbf{1 : 0 . 2}$ & $\mathbf{1 : 0 . 4}$ & $\mathbf{1 : 0 . 6}$ & $\mathbf{1 : 0 . 8}$ \\
\hline Exchangeable state & $-94 \%$ & $-77 \%$ & $-85 \%$ & $-80 \%$ \\
Carbonate binding state & $-85 \%$ & $-80 \%$ & $60 \%$ & $-81 \%$ \\
Iron-manganese combined state & $-99 \%$ & $-100 \%$ & $-98 \%$ & $-97 \%$ \\
Organic sulfide binding state & $24 \%$ & $-76 \%$ & $-36 \%$ & $-48 \%$ \\
Residual state & $15 \%$ & $56 \%$ & $30 \%$ & $26 \%$ \\
\hline
\end{tabular}

According to Figure 11 and Table 19, for Zn element, after leaching the carbonate binding state and residual state increased significantly. The residual state increased with an average of $1152 \%$ in mass. The increasing of carbonate binding state was $137 \%$ on average. The proportions of the other three states were all significantly decreased, especially the iron-manganese combined state was almost eliminated, with an average decreasing of $99 \%$. The decreasing of exchangeable state was $71-92 \%$. In addition, the decreasing of the organic sulfide binding state ranged from $44 \%$ to $75 \%$. The results demonstrated that after leaching most Zn element exited in backfill material mainly as residual state, a little bit organic sulfide binding state, and few carbonate binding states. Most of the $\mathrm{Zn}$ element had been significantly restricted in migration under hydrodynamic leaching.

Table 19. Mass ratio variation of $\mathrm{Zn}$ occurrence states before and after leaching.

\begin{tabular}{ccccc}
\hline State of Occurrence/Proportion & $\mathbf{1 : 0 . 2}$ & $\mathbf{1 : 0 . 4}$ & $\mathbf{1 : 0 . 6}$ & $\mathbf{1 : 0 . 8}$ \\
\hline Exchangeable state & $-71 \%$ & $-92 \%$ & $-80 \%$ & $-80 \%$ \\
Carbonate binding state & $28 \%$ & $96 \%$ & $259 \%$ & $163 \%$ \\
Iron-manganese combined state & $-99 \%$ & $-99 \%$ & $-99 \%$ & $-98 \%$ \\
Organic sulfide binding state & $-75 \%$ & $-74 \%$ & $-44 \%$ & $-66 \%$ \\
Residual state & $3829 \%$ & $515 \%$ & $168 \%$ & $97 \%$ \\
\hline
\end{tabular}




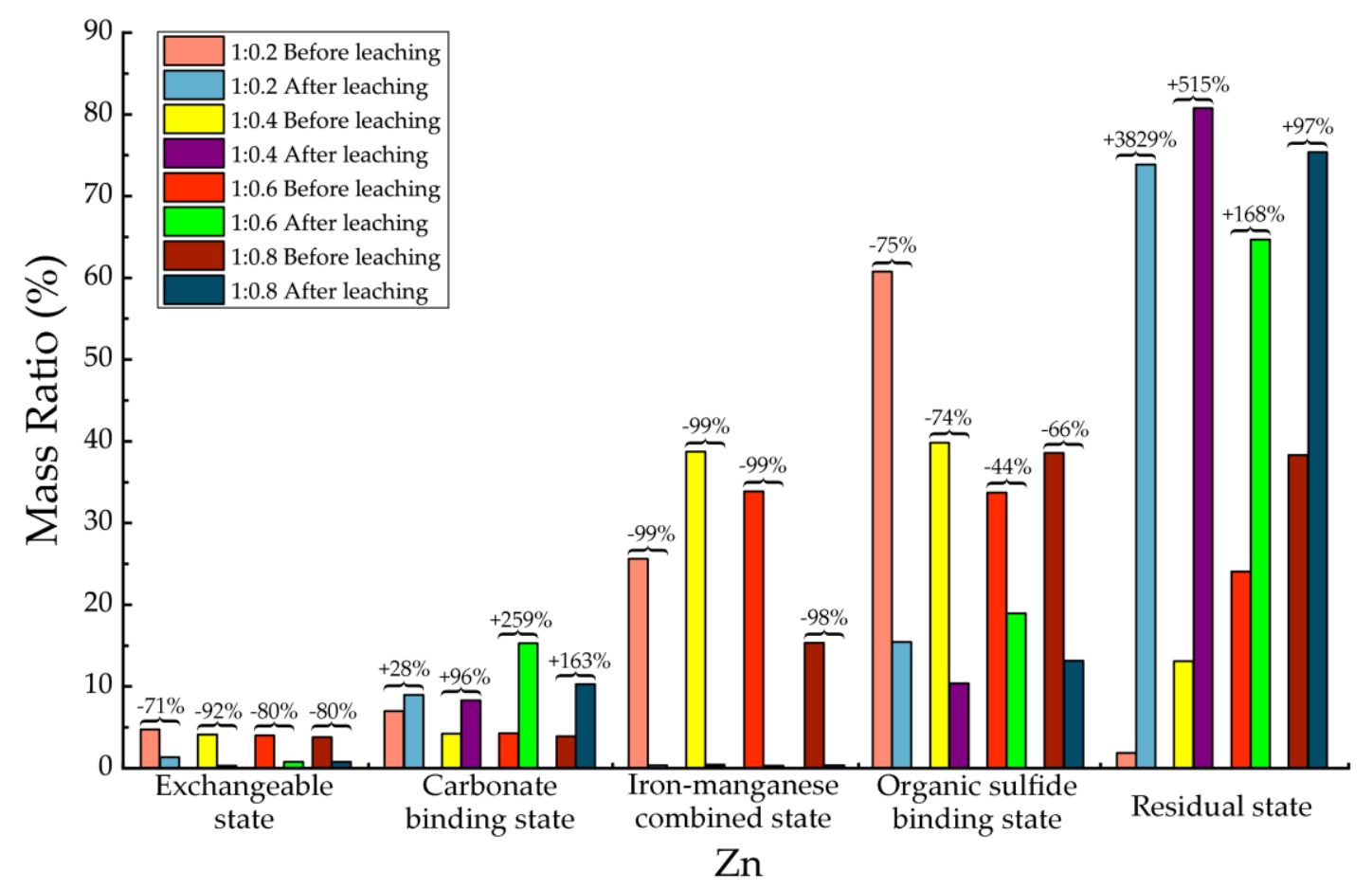

Figure 11. Sequential extraction of $\mathrm{Zn}$ before and after leaching in different occurrence states.

\section{Discussion}

Dai et al. have pointed out that, according to the quality of coal resources in Xuzhou, environmental risks exist during the whole life cycle of coal production and use because of the contents of trace metals [2]. In addition, in Xuzhou, former reclaimed mining subsidence areas by using only gangue material, the content of trace metals like $\mathrm{Cd}, \mathrm{Cr}, \mathrm{Cu}, \mathrm{Pb}$, etc. exceeded China soil quality standards $[4,5,7]$. In this work, we presented a novel method and case study to restrict the migration ability of trace metal elements in gangues by using another kind of coalmine solid waste-fly ashes from coal combustion. This study verified that after leaching the residual states of $\mathrm{Cd}$, $\mathrm{Cr}, \mathrm{Ni}$ and $\mathrm{Zn}$ in backfill materials was greatly increased than before leaching; the residual state and carbonate binding state of $\mathrm{Mn}$ were also significantly increased while its iron-manganese combined state decreased greatly. The residual state of $\mathrm{Pb}$ also increased to a certain extent after leaching, and its iron-manganese combined state decreased to almost none; the carbonate binding state of $\mathrm{Cu}$ after leaching was significantly decreased, while its iron-manganese combined state and residual state increased greatly. After leaching, $\mathrm{Cd}, \mathrm{Ni}, \mathrm{Zn}, \mathrm{Cr}$, and $\mathrm{Pb}$ are significantly restricted to be released into the environment than that before leaching, and $\mathrm{Cu}, \mathrm{Mn}$ could still have little opportunities to migrate in reclamed land base.

Under dynamical leaching from natural precipitation, $\mathrm{Cd}, \mathrm{Cr}, \mathrm{Ni}, \mathrm{Pb}$ and $\mathrm{Zn}$ in backfill material were mainly presented in residual state, which demonstrated that these trace metal elements were significantly restricted in migration and they have low risks to environment. This finding has good agreement with previous studies. Matong et al. reported that in the soil of Free State, South Africa, Cd was found to perform more actively than other trace elements, with main reason of anthropogenic industries instead of minerals' releasing [44], and like the results in this study, trace elements with inert mineral binding state had low migration ability. Yang et al. reported in Xinhua coalmine area of Guizhou, China, the main occurrence state of tested trace elements was also residual state, except $\mathrm{Cd}$, which also performs more active than other trace elements because the local gangues were easily to be weathered, and weathering effect could increase the activity of $\mathrm{Cd}$. However, in our backfill material design, air could be effectively isolated by using fine fly ashes, to avoid weathering effect [45]. Bian et al. pointed out that with the weathering and leaching effect in mining rocks, the $\mathrm{pH}$ could 
be decreased and the trace elements $\mathrm{Zn}, \mathrm{Cu}, \mathrm{Cd}, \mathrm{Cr}$, and $\mathrm{Pb}$ were released in to environment. Lime material was suitable to reduce the acidity [1,27]. In our study, by using fly ash, the same effect as with lime could be achieved. Zhou et al. reported that in Huainan city which locates about $300 \mathrm{~km}$ south of Xuzhou, the situation was most of the trace elements were strongly associated with sulfide minerals, which could also be easily released under oxidation and leaching effect, only leaching effect also had low potential of environmental risks [46]. According to our research and previous research, the avoidance of comprehensive effect by oxidation and natural leaching is important, gangues with adequate fly ash backfilled land area could prevent air from permeation, and the reconstructed overlying soil layer could also separate the reclaimed land base with air, therefore our method has low risks to the environment.

According to study results, $\mathrm{Mn}$ and $\mathrm{Cu}$ still have potential risk to the environment, since the carbonate binding state, iron-manganese combined state and organic sulfide binding state were still major remnants. As Sungur et al. has mentioned that in Turkey, once these elements had entered overlying soil, these states can be oxidized easily under the natural conditions and migrate into the environment [47]. Another previous study from Tang et al. reported that in the Huainan coalmine area, $\mathrm{Mn}$ could be a moderate threat to the environment, since the iron-manganese combined state were more easily to be oxidized than other states [48], here we have had very similar results, Mn still had migration potential due to increasing of carbonate binding state. In addition, Matong et al. have also reported similar results [44]. Previous studies have also indicated that trace metals could cause pollutions to soil under strong acidic conditions, especially with participation of sulfide minerals. However, in our research, alkaline fly ash was used to modify gangue, which could keep the reclaimed land base in alkaline states and restrict the migration risks. O'Connor et al. also reported that with the decreasing of $\mathrm{pH}$, the adsorption of trace metals in soil also decreased and further led to migration [15]. Zhou et al. also revealed that $C d$ has low risk to environment in alkaline condition [46], which supports our results. Sungur et al. revealed that $\mathrm{Pb}$ possessed high mobility and consequent more availability in acid soluble and reducible fractions, which means that $\mathrm{Pb}$ can cause environmental pollution easily [47], but in our research, residue state of $\mathrm{Pb}$ took up almost $90 \%$, other fractions except organic sulfides state were basically none, since fly ash brought the avoidance of acidity in reclaimed land. Wang et al. reported a novel efficient method by using $\mathrm{MgO}$, cement and ground granulated blast-furnace slag as binding agent for trace metals solidification in soil, especially for $\mathrm{Cu}, \mathrm{Zn}$, and $\mathrm{Ni}$, which also supported the relationship between $\mathrm{pH}$ values and leachability of trace metals, this results also supported our method by using fly ash, which is similar to cement with certain contents of $\mathrm{MgO}[20,21]$.

Generally, isolation of coalmine wastes from air i.e., weathering and oxidation effect of natural environment is also critical to restriction of trace element migration. Gangues modification with fly ash could fulfill this condition. In this research we studied seven environmentally sensitive trace metals, some other elements like mercury $(\mathrm{Hg})$, arsenic (As), which could also cause serious environment pollutions were not studied, since they are rare found in local strata of Xuzhou Qishan-Quantai coalmine area. Trace elements like $\mathrm{Mn}$ and $\mathrm{Cu}$ were still not restricted significantly, in future works, more trace elements, more proportioning of backfill materials from different coalmines should be tested. Yin et al. reported by using flay ash in reclamation, it could have influence on physical structure of reconstructed overlaying soil, by using sludge and fungi could restore the soil aggregations and the soil organic carbon [6]. Therefore in future studies we should also considered the optimization of soil quality, at the same time of contamination control.

\section{Conclusions}

Through this study, it has been verified that the hydrodynamic migration activity of tested seven trace metals $\mathrm{Cu}, \mathrm{Zn}, \mathrm{Pb}, \mathrm{Cd}, \mathrm{Cr}, \mathrm{Mn}$ and $\mathrm{Ni}$ in gangue-fly ash backfill materials had been significantly restricted. Under the driving of natural leaching effect of precipitation, although the migration of the tested trace metal elements was downstream, which went always deeper inside the backfill reclaimed land base of subsided area, the occurrence state of most trace metal elements was transformed to 
be much more inactive in releasing and migration. Among all tested trace metal elements, Mn performed different from others, which was mainly transformed from iron-manganese combined state to carbonate binding state, it could lead to a little bit increasing in its migration ability. Hence in a further study, specific agents to inhibit activity of Mn element could be added into the backfill material. Gangue-fly ash backfill materials with proportions of 1:0.2 and 1:0.4 performed high transformation efficiency of trace metals from active states to inert states than proportion of 1:0.6 and 1:0.8, which meant that excessive fly ash has negative effects on occurrence state transformation. $\mathrm{Cd}$ was found to have nearly no potential risks, and $\mathrm{Cu}$ was found to be bond to carbonates, Fe and $\mathrm{Mn}$ oxides as well as organic sulfides, both results are in good agreement with relative studies, such as Marquez et al.

The simulated groundwater level in this research was $-2 \mathrm{~m}$, which was much higher than in the local area. With the increasing of groundwater depth, with the increasing of migration distance and period, more trace metals are believed to be transformed in inert and in active states. However, there was still a certain amount of trace metals existed in iron-manganese combined state and organic sulfide binding state, these two states might be activated if the $\mathrm{pH}$-value of groundwater changed. In old coalmine waste dumps, acid leachate is always produced with the inside infiltration of oxygen. Hence the reconstructed overlying soil layer must have appropriate thickness, in order to prevent oxygen from infiltration and avoid the producing of acid leachate. Gangue and fly ash are easily acquired in coalmine area, by using gangue-fly ash backfill materials it can solve both gangue dumping and land subsidence problems. In future, based on this case study, gangue-fly ash backfill materials from more coalmine areas in China should also be studied.

Author Contributions: J.H. and Z.Z. conceived and designed the experiments; C.X. and P.W. made the Validation. C.X., Z.Z. and P.W. performed the experimental work; J.H. and Z.Z. analyzed the data; all authors contributed to the writing, reviewing of the manuscript, as well as the interpretation of the experimental results.

Funding: This work was funded by the projects National Natural Science Foundation of China (Grant No. 51504241, U1710120) and the National Key Research and Development Project (Grant No. 2016YFC0501107).

Acknowledgments: The authors thank the study participants and teachers for their cooperation and support. We also thank the National Natural Science Foundation of China and China Ministry for Science and Technology for their financial supports.

Conflicts of Interest: The authors declare no conflict of interest.

\section{References}

1. Bian, Z.F.; Miao, X.X.; Lei, S.G.; Chen, S.E.; Wang, W.F.; Struthers, S. The challenges of reusing mining and mineral-processing wastes. Science 2012, 337, 702-703. [CrossRef] [PubMed]

2. Dai, W.T.; Dong, J.H.; Yan, W.L.; Xu, J.R. Study on each phase characteristics of the whole coal life cycle and their ecological risk assessment-a case of coal in china. Environ. Sci. Pollut. Res. Int. 2017, 24, 1296-1305. [CrossRef] [PubMed]

3. Wang, J.M.; Qin, Q.; Hu, S.J.; Wu, K.N. A concrete material with waste coal gangue and fly ash used for farmland drainage in high groundwater level areas. J. Clean. Prod. 2015, 112, 631-638. [CrossRef]

4. Dong, J.H.; Yu, M.; Bian, Z.F.; Wang, Y.; Di, C.L. Geostatistical analyses of trace metal distribution in reclamed mine land in Xuzhou, China. Environ. Earth Sci. 2011, 62, 127-137. [CrossRef]

5. Dong, J.H.; Yu, M.; Bian, Z.F.; Zhao, Y.D.; Cheng, W. The safety study of trace metal pollution in wheat planted in reclamed soil of mining areas in Xuzhou, China. Environ. Earth Sci. 2012, 66, 673-682. [CrossRef]

6. Yin, N.N.; Zhang, Z.; Wang, L.P.; Qian, K.M. Variations in organic carbon, aggregation, and enzyme activities of gangue-fly ash-reconstructed soils with sludge and arbuscular mycorrhizal fungi during 6-year reclamation. Environ. Sci. Pollut. Res. Int. 2016, 23, 17840. [CrossRef] [PubMed]

7. Dong, J.H.; Dai, W.T.; Xu, J.R.; Li, S.N. Spectral estimation model construction of trace metals in mining reclamation areas. Int. J. Environ. Res. Public Health 2016, 13, 640. [CrossRef] [PubMed]

8. Dong, J.H.; Dai, W.T.; Shao, G.Q.; Xu, J.R. Ecological network construction based on minimum cumulative resistance for the city of nanjing, china. ISPRS Int. J. Geo-Inf. 2015, 4, 2045-2060. [CrossRef]

9. Burchartkorol, D.; Fugiel, A.; Czaplickakolarz, K.; Turek, M. Model of environmental life cycle assessment for coal mining operations. Sci. Total Environ. 2016, 562, 61-72. [CrossRef] [PubMed] 
10. Bian, Z.F.; Lei, S.G.; Jin, D.; Wang, L. Several basic scientific issues related to mined land reclamation. J. China Coal Soc. 2018, 43, 190-197.

11. Huang, J.; Tian, C.Y.; Xing, L.F.; Bian, Z.F.; Miao, X.X. Green and sustainable mining: Underground coal mine fully mechanized solid dense stowing-mining method. Sustainability 2017, 9, 1418. [CrossRef]

12. Xu, L.J.; Huang, C.; Zhang, R.Q.; Liu, H.P.; Yan, J.P.; Meuser, H.; Makowsky, L. Physical and chemical properties and distribution characteristics of trace metals in reclamed land filled with coal gangue. Trans. Chin. Soc. Agric. Eng. 2014, 30, 211-219.

13. Dong, J.H.; Bian, Z.F.; Wang, H.F.; Wang, H. Study on Contents of Trace metals in Filling Reclamation Soil in Xuzhou Mining Region. J. Soil Water Conserv. 2007, 21, 180-182.

14. Mohan, S.; Gandhimathi, R. Removal of trace metal ions from municipal solid waste leachate using coal fly ash as an adsorbent. J. Hazard. Mater. 2009, 169, 351-359. [CrossRef] [PubMed]

15. O'Connor, D.; Peng, T.; Zhang, J.; Tsang, D.; Alessi, D.; Shen, Z.; Bolan, N.; Hou, D. Biochar application for the remediation of trace metal polluted land: A review of in situ field trials. Sci. Total Environ. 2018, 619-620, 815-826. [CrossRef] [PubMed]

16. Sočo, E.; Kalembkiewicz, J. Adsorption of nickel(ii) and copper(ii) ions from aqueous solution by coal fly ash. J. Environ. Chem. Eng. 2013, 1, 581-588. [CrossRef]

17. Singh, M.; Siddique, R. Properties of concrete containing high volumes of coal bottom ash as fine aggregate. J. Clean. Prod. 2015, 91, 269-278. [CrossRef]

18. O'Connor, D.; Peng, T.; Li, G.; Wang, S.; Duan, L.; Mulder, J.; Cornelissen, G.; Cheng, Z.; Yang, S.; Hou, D. Sulfur-modified rice husk biochar: A greenmethod for the remediation of mercury contaminated soil. Sci. Total Environ. 2018, 621, 819-826. [CrossRef] [PubMed]

19. Ghorbani, Y.; Seng, H.K. A review of sustainable development in the Chilean mining sector: Past, present and future. Int. J. Surface Min. Reclam. Environ. 2016, 31, 137-165. [CrossRef]

20. Wang, F.; Jin, F.; Shen, Z.; Al-Tabbaa, A. Three-year performance of in-situ mass stabilised contaminated site soils using MgO-bearing binders. J. Hazard. Mater. 2016, 285, 46-52. [CrossRef] [PubMed]

21. Wang, F.; Wang, H.; Jin, F.; Al-Tabbaa, A. The performance of blended conventional and novel binders in the in-situ stabilisation/solidification of a contaminated site soil. J. Hazard. Mater. 2015, 318, 302-307. [CrossRef] [PubMed]

22. Weber, J.; Straczynńska, S.; Kocowicz, A.; Gilewska, M.; Bogacz, A.; Gwiżdż, M.; Debicka, M. Properties of soil materials derived from fly ash 11 years after revegetation of post-mining excavation. Catena 2017, 148, 35-39. [CrossRef]

23. Żołnierz, L.; Weber, J.; Gilewska, M.; Straczyńska, S.; Pruchniewicz, D. The spontaneous development of understory vegetation on reclamed and afforested post-mine excavation filled with fly ash. Catena 2016, 136, 84-90. [CrossRef]

24. Li, J.; Smart, R.S.; Schumann, R.C.; Gerson, A.R.; Levay, G. A simplified method for estimation of jarosite and acid-forming sulfates in acid mine wastes. Sci. Total Environ. 2007, 373, 391. [CrossRef] [PubMed]

25. Pandey, S.K.; Bhattacharya, T.; Chakraborty, S. Metal phytoremediation potential of naturally growing plants on fly ash dumpsite of Patratu thermal power station, Jharkhand, India. Int. J. Phytoremediat. 2016, 18, 87-93. [CrossRef] [PubMed]

26. Ayala, J.; Fernández, B. A case study of landfill leachate using coal bottom ash for the removal of $\mathrm{cd}^{2+}, \mathrm{zn}^{2+}$ and $\mathrm{ni}^{2+}$. Metals 2016, 6, 300. [CrossRef]

27. Bian, Z.F.; Dong, J.H.; Lei, S.G.; Leng, H.L.; Mu, S.G.; Hui, W. The impact of disposal and treatment of coal mining wastes on environment and farmland. Environ. Geol. 2009, 58, 625-634. [CrossRef]

28. Harnischmacher, S.; Zepp, H. Mining and its impact on the earth surface in the Ruhr District (Germany). Z. Geomorphol. 2014, 58, 3-22. [CrossRef]

29. Yang, L.; Song, J.F.; Bai, X.; Song, B.; Wang, R.D.; Zhou, T.H.; Jia, J.L.; Pu, H.X. Leaching behavior and potential environmental effects of trace elements in coal gangue of an open-cast coal mine area, Inner Mongolia, China. Minerals 2016, 6, 50. [CrossRef]

30. Parbhakar-Fox, A. Geoenvironmental characterisation of heap leach materials at abandoned mines: Croydon au-mines, QLD, Australia. Minerals 2016, 6, 52. [CrossRef]

31. Zhang, Q.L.; Chen, Q.S.; Wang, X.M. Cemented backfilling technology of paste-like based on aeolian sand and tailings. Minerals 2016, 6, 132. [CrossRef] 
32. Zuo, Q.T.; Luo, Z.L.; Ding, X.Y. Harmonious development between socio-economy and river-lake water systems in Xiangyang city, China. Water 2016, 8, 509. [CrossRef]

33. Wang, H.; Han, B.P.; Bian, Z.F. Simulation Research on Water Upright Movement in Reclamed Soil by Filling. J. China Univ. Min. Technol. 2007, 36, 690-695.

34. Xu, L.J.; Xu, S.W.; Yang, X.F.; Yan, J.P.; Meuser, H.; Makowsky, L. Study on Distribution Character of Physical and Chemical Properties and Trace metals in Reclamed Land Filled with Fly Ash: A Case Study of Reclamed Land of Luohe Power Plant in Huainan City. J. Agro-Environ. Sci. 2012, 31, 2352-2360.

35. Wang, F.; Chen, X.Y.; Tan, H.Y.; Yu, J.H.; Liu, Y. Soluble Potassium Transport and Concentration Change in Reclamed Soil Filled with Fly Ash. J. Henan Agric. Sci. 2015, 44, 59-64.

36. Shiva, A.H.; Bennett, W.W.; Welsh, D.T.; Teasdale, P.R. In situ evaluation of DGT techniques for measurement of trace metals in estuarine waters: A comparison of four binding layers with open and restricted diffusive layers. Environ. Sci. Process. Impacts 2016, 18, 51-63. [CrossRef] [PubMed]

37. Öhlander, B.; Forsberg, J.; Österlund, H.; Ingri, J.; Ecke, F.; Alakangas, L. Fractionation of trace metals in a contaminated freshwater stream using membrane filtration, ultrafiltration, DGT and transplanted aquatic moss. Geochem. Explor. Environ. Anal. 2016, 12, 303-312. [CrossRef]

38. Wang, S.F.; Han, P.; Wang, J.H.; Lu, A.X.; Li, F. Application of X-ray fluorescence spectrometry on the detection of heavy metals in soil. J. Food Saf. Qual. 2017, 7, 4394-4400.

39. Chong, T.; Zhang, J.; Zhao, Y.; Gupta, R. Understanding of mineralogy and residence of trace elements in coals via a novel method combining low temperature ashing and float-sink technique. Int. J. Coal Geol. 2014, 131, 162-171.

40. Race, M.; Ferraro, A.; Fabbricino, M.; La, A.M.; Panico, A.; Spasiano, D.; Tognacchini, A.; Pirozzi, F. Ethylenediamine-n, $n^{\prime}$-disuccinic acid (edds)-enhanced flushing optimization for contaminated agricultural soil remediation and assessment of prospective $\mathrm{cu}$ and $\mathrm{Zn}$ transport. Int. J. Environ. Res. Public Health 2018, 15, 543. [CrossRef] [PubMed]

41. Martins, T.A.; Leitão, T.E.; Carvalho, M.D.R. Assessment of Wastewater Contaminants Retention for a Soil-aquifer Treatment System Using Soil-column Experiments. Water Rock Interact. 2017, 17, 332-335. [CrossRef]

42. Meisinger, J.J.; Ricigliano, K.A. Nitrate leaching from winter cereal cover crops using undisturbed soil-column lysimeters. J. Environ. Qual. 2017, 46, 576. [CrossRef] [PubMed]

43. Marquez, J.E.; Pourret, O.; Faucon, M.P.; Weber, S.; Hoàng, T.B.H.; Martinez, R.E. Effect of cadmium, copper and lead on the growth of rice in the coal mining region of Quang Ninh, Cam-Pha (vietnam). Sustainability 2018, 10, 1758. [CrossRef]

44. Matong, J.M.; Nyaba, L.; Nomngongo, P.N. Fractionation of trace elements in agricultural soils using ultrasound assisted sequential extraction prior to inductively coupled plasma mass spectrometric determination. Chemosphere 2016, 154, 249-257. [CrossRef] [PubMed]

45. Yang, Y.; Ji, H.B. A study on chemical forms and leaching characteristics of trace elements in coal gangue from xinhua coal mine in Guizhou Province, China. Earth Environ. 2016, 44, 36-46.

46. Zhou, C.; Liu, G.; Fang, T.; Sun, R.; Wu, D. Leaching characteristic and environmental implication of rejection rocks from Huainan Coalfield, Anhui Province, China. J. Geochem. Explor. 2014, 143, 54-61.

47. Sungur, A.; Soylak, M.; Yilmaz, E.; Yilmaz, S.; Ozcan, H. Characterization of heavy metal fractions in agricultural soils by sequential extraction procedure: The relationship between soil properties and heavy metal fractions. J. Soil Contamin. 2015, 24, 1-15. [CrossRef]

48. Tang, Q.; Li, L.; Zhang, S.; Zheng, L.; Miao, C. Characterization of heavy metals in coal gangue-reclaimed soils from a coal mining area. J. Geochem. Explor. 2018, 186, 1-11. [CrossRef]

(C) 2018 by the authors. Licensee MDPI, Basel, Switzerland. This article is an open access article distributed under the terms and conditions of the Creative Commons Attribution (CC BY) license (http:/ / creativecommons.org/licenses/by/4.0/). 